Published in final edited form as:

Small. 2017 December ; 13(47): . doi:10.1002/smll.201701949.

\title{
Porous Electrospun Fibers with Self-Sealing Functionality: An Enabling Strategy for Trapping Biomacromolecules
}

\author{
Dr. Jin Zhang, \\ College of Polymer Science and Engineering, State Key Laboratory of Polymer Materials \\ Engineering, Sichuan University, Chengdu 610065, P. R. China. Division of Engineering in \\ Medicine, Department of Medicine, Brigham and Women's Hospital, Harvard Medical School, \\ Cambridge, MA 02139, USA
}

\section{Dr. Ting Zheng,}

Division of Engineering in Medicine, Department of Medicine, Brigham and Women's Hospital, Harvard Medical School, Cambridge, MA 02139, USA

\section{Dr. Emine Alarçin,}

Division of Engineering in Medicine, Department of Medicine, Brigham and Women's Hospital, Harvard Medical School, Cambridge, MA 02139, USA

\section{Dr. Batzaya Byambaa,}

Division of Engineering in Medicine, Department of Medicine, Brigham and Women's Hospital, Harvard Medical School, Cambridge, MA 02139, USA

\section{Dr. Xiaofei Guan,}

Division of Engineering in Medicine, Department of Medicine, Brigham and Women's Hospital, Harvard Medical School, Cambridge, MA 02139, USA

\section{Prof. Jianxun Ding,}

Key Laboratory of Polymer Ecomaterials, Changchun Institute of Applied Chemistry, Chinese Academy of Sciences, Changchun 130022, P. R. China

Dr. Yu Shrike Zhang, and

Division of Engineering in Medicine, Department of Medicine, Brigham and Women's Hospital, Harvard Medical School, Cambridge, MA 02139, USA

\section{Prof. Zhongming Li}

College of Polymer Science and Engineering, State Key Laboratory of Polymer Materials Engineering, Sichuan University, Chengdu 610065, P. R. China

\author{
Abstract \\ Correspondence to: Jianxun Ding; Yu Shrike Zhang; Zhongming Li \\ The ORCID identification number(s) for the author(s) of this article can be found under https://doi.org/10.1002/smll.201701949. \\ Conflict of Interest \\ The authors declare no conflict of interest. \\ Supporting Information \\ Supporting Information is available from the Wiley Online Library or from the author.
}


Stimuli-responsive porous polymer materials have promising biomedical application due to their ability to trap and release biomacromolecules. In this work, a class of highly porous electrospun fibers is designed using polylactide as the polymer matrix and poly(ethylene oxide) as a porogen. Carbon nanotubes (CNTs) with different concentrations are further impregnated onto the fibers to achieve self-sealing functionality induced by photothermal conversion upon light irradiation. The fibers with $0.4 \mathrm{mg} \mathrm{mL}^{-1}$ of CNTs exhibit the optimum encapsulation efficiency of model biomacromolecules such as dextran, bovine serum albumin, and nucleic acids, although their photothermal conversion ability is slightly lower than the fibers with $0.8 \mathrm{mg} \mathrm{mL}^{-1}$ of CNTs. Interestingly, reversible reopening of the surface pores is accomplished with the degradation of PLA, affording a further possibility for sustained release of biomacromolecules after encapsulation. Effects of CNT loading on fiber morphology, structure, thermal/mechanical properties, degradation, and cell viability are also investigated. This novel class of porous electrospun fibers with self-sealing capability has great potential to serve as an enabling strategy for trapping/release of biomacromolecules with promising applications in, for example, preventing inflammatory diseases by scavenging cytokines from interstitial body fluids.

\section{Keywords}

biomacromolecules; carbon nanotubes; porous electrospun fibers; self-closure; trapping and release

\section{Introduction}

Development of porous polymer materials possessing high surface area, low density, and large loading capacity has attracted increasing attention in numerous applications, including ion exchange, microreactor, microsensor, scaffold for tissue engineering, and capsule for drug delivery. ${ }^{[1]}$ In particular, the stimuli-responsive porous polymer materials are among the most appealing materials that can be easily controlled by external signals. ${ }^{[2]}$ For example, Credi and co-workers fabricated the functional electrospun nanocomposites that could give response to both optical (ultraviolet-visible [UV-vis] light) and chemical (baseacid) stimuli by embedding the rotaxane-type molecular complexes into the polymer nanofibers. ${ }^{[2,3]}$ In the fields of drug delivery and general biomedicine, significant efforts have also been focused on designing such stimuli-responsive porous materials owing to their enhanced tunability of biomolecule release and thus improved therapeutic efficacy. ${ }^{[4]}$ For instance, porous silicon-poly ( $N$-isopropylacrylamide), a thermoresponsive inorganicorganic composite material, was able to significantly alter the release rate of anticancer drug camptothecin by modulating the temperature around its lower critical solution temperature. [5] Yang et al. fabricated a mesoporous silica framework that was incorporated with gold nanorods (AuNRs) and surface-functionalized with DNA aptamer; the local rapid increase in temperature caused by the photothermal effect of AuNRs upon near infrared (NIR) light irradiation led to the dehybridization of the linkage DNA helix, allowing for release of the entrapped guest molecules. ${ }^{[4 a]}$

Among these stimuli-sensitive porous polymer materials, an attractive but relatively unexplored area is the manipulation of self-sealing pores that can achieve closure on 
demand. Such smart structure is able to seal their pores in a controlled manner by responding to an externally applied stimulus, such as $\mathrm{pH}$, temperature, or local light absorption. In a most recent demonstration, the highly porous poly(lactide-co-glycolide) (PLGA) microspheres with an outstanding pore-sealing capability were fabricated by a novel oil-in-water emulsion technique. ${ }^{[6]}$ In their system, isopropyl formate was used as the antisolvent for PLGA to obtain a porous structure, where the successful loading of lysozyme and fluorescein isothiocyanate-dextran (FITC-Dex) into the microspheres could be realized by simply equilibrating the pore self-sealing microspheres with their aqueous solutions. Pore self-closure was realized by thermal treatment to a temperature above the glass transition temperature $\left(T_{\mathrm{g}}\right)$ of PLGA.

Phase transition induced by heat treatment of the ambient environment has already become one of the main strategies to close the pores of polymer materials, ${ }^{[7]}$ but such a heating process is generally slow and not applicable in most biological systems. Alternatively, the local heating through photothermal conversion not only enables phase transition of the polymer matrix, but also minimizes damage to the bulk surrounding that would otherwise be caused by collective heating. ${ }^{[8]}$ In particular, applications of carbon nanotubes (CNTs) with photothermal conversion ability have been found available for rapid self-closure by remote triggers of light irradiation, due to their outstanding photothermal effect of high photoabsorption property and excellent thermal conductivity. ${ }^{[9]}$ For example, Miyako et al. demonstrated that the NIR laser-triggered CNTs could operate as the exothermic nanomaterials, potentially serving as an efficient photothermal conversion tool for controlling the phase transition of smart polymer gels. ${ }^{[10]}$ Moreover, in a recent study, a direct single-step method was used to fabricate porous polylactide (PLA) macroparticles with multiple interconnected chambers assembled with single-walled CNTs. ${ }^{[11]}$ It has been shown that these CNT-impregnating PLA macroparticles as smart vehicles could close the surface pores under NIR irradiation for controlled encapsulation of free biomacromolecules. Except for the local heating caused by the photothermal conversion of CNTs, the selfsealing capability may also be achieved with localized reactions. The nanoimprinting lithography technique was employed to fabricate gold nanofinger substrates that composed of highly ordered and free-standing fingers. ${ }^{[12]}$ These open fingers were then exposed to a target solution and blow-dried with nitrogen. During the evaporation of the solvent, a selfsealing process of the flexible and high-aspect ratio nanofingers was observed, which was driven by the microcapillary forces and finally realized an active trapping of the analyte molecules among closed fingertips.

Here we introduce a convenient, stable, and generally applicable electrospinning/leaching strategy to fabricate PLA/CNT composite fibers with controllable surface pores. FITC-Dex, tetramethylrhodamine-bovine serum albumin (TMR-BSA), and fluorescein-labeled DNA (FLU-DNA) were chosen as the model agents to determine the encapsulation capability of biomacromolecules into the porous electrospun fibers. Carboxyl-functionalized CNTs were utilized in the current study to realize the pore self-closure through the photothermal conversion ability. It was demonstrated that the fibers with $0.4 \mathrm{mg} \mathrm{mL}^{-1}$ of CNTs on the surface exhibited the optimal photothermal encapsulation efficiency and acted as the smart carrier to capture and hold free molecules from the surrounding aqueous solutions of FITCDex, TMR-BSA, or FLU-DNA upon UV light irradiation. Notably, through gradual 
degradation of the polymer matrix a reversible reopening of the surface pores was observed, providing the possibility of sustained release after encapsulation. Compared with the reported single-step emulsion method, our strategy has the ability to fabricate highly porous structures with controlled pore sizes in a simpler way without high shear or high-energy mixer, and potentially at larger scales. It is envisioned that this approach can be generalized for the stimuli-responsive encapsulation and controlled release of biomacromolecules in the future, expediting the translational potential of porous materials such as elimination of uncontrolled inflammatory diseases by reducing the expression of undesired nucleic acids and then extending their release into the local microenvironment after trapped.

\section{Results and Discussion}

\subsection{Characterizations of Electrospun Fibers with Different Poly(Ethylene Oxide) (PEO) Contents}

In the present study, a direct and generally applicable strategy was developed to fabricate the porous PLA/CNT fibers with controlled pore sizes (Figure 1). Herein, a hydrophilic polymer PEO was chosen as the porogen, leading to the generation of electrospun fibers with porous structures after leaching, in addition to the pores formed among the fibers. It is well-known that the final structure of porous electrospun fibers strongly depends on both the phase separation process and weight ratio of PLA/PEO. ${ }^{[13]}$ In the current fabrication technique, the PEO phase was used with different weight ratios to achieve a desired porous structure. Figure 2A displays representative scanning electron microscopy (SEM) images of the electrospun fibers at different PLA/PEO weight ratios after PEO dissolution. The uniform fibrous networks were achieved for all the fibers. More interestingly, the enlarged images indicated that all these electrospun fibers possessed highly porous structures, proved by the coexistence of both pores present on the fibers and those in the interconnected networks of the fibers. Additionally, the morphology of the pores on the fibers seemed to change with the different PEO fractions. A ravine-like nanoporous structure was present on the fibers fabricated with a high PEO content (PLA:PEO = 3:7). Under such a condition the overly high weight ratio of $\mathrm{PEO}$ would inevitably cause the formation of many tiny surface pores and some of them were connected into the trench, as indicated in the SEM image. By decreasing the PEO content to 5:5 of PLA:PEO, a more interconnected nanoporous structure was presented on the fibers potentially due to the improved phase separation of $\mathrm{PEO}$ and formation of PLA/PEO co-continuous structure. ${ }^{[14]}$ It is anticipated that, following the immersion of the electrospun fibers into water, the phase-separated PEO should leach into the aqueous phase leading to formation of the nanosized pores on the fibers. However, it is possible that PEO in the fibers fabricated at the weight ratio of PLA/PEO of 7:3 could not be completely washed away because some PEO phases were entirely encapsulated in the bulk of PLA fibers.

The pore sizes were further quantified (Figure 2B). In accordance with SEM images, fibers with a PLA/PEO weight ratio of 3:7 led to the smallest pore dimension $(90 \pm 11 \mathrm{~nm})$ on the fibers, which was $\approx 65 \%$ and $25 \%$ lower than those for fibers produced with the weight ratios of 5:5 $(260 \pm 5 \mathrm{~nm})$ and 7:3 $(120 \pm 9 \mathrm{~nm})$, respectively. The polymer compositions are also crucial parameters affecting the diameter of the electrospun fibers. The average diameters 
and frequency distributions of the electrospun PLA fibers fabricated from different PLA/PEO weight ratios are shown in Figure 2C. The average fiber diameter increased from $1.10 \pm 0.27$ to $2.19 \pm 0.23 \mu \mathrm{m}$ as the PEO content was decreased from 70 to $30 \mathrm{wt} \%$. This apparent rise in fiber diameter upon decreasing PEO content might be ascribed to the decreased solution conductivity, which causes a weaker electrical drag force that can be used for elongating the fiber along its length. ${ }^{[15]}$ As is well-known, the size of the pores and the distribution of the fibers are vital factors determining the matrix degradation, biomacromolecule encapsulation/release, and host responses. ${ }^{[16]}$

The thermal behaviors of the electrospun fibers such as crystallinity and melting point were also affected by the variation in the PLA/PEO weight ratios, although the PEO was mostly removed by water. As shown in Figure 2D, the crystallization ability of the composite fibers was enhanced with the increasing content of PEO in the PLA phase. There was an obvious increase in the crystallinity and cold-crystallization temperature from $69.7 \%$ to $76.1 \%$ and 109.3 to $112.1{ }^{\circ} \mathrm{C}$, respectively, as weight ratio of PLA/PEO was changed from 7:3 to 3:7. In previous reports, the mobile PEO chains in the amorphous state acted as effective plasticizers for PLA, which could lead to increases in the crystallization degree and coldcrystallization temperature. ${ }^{[17]}$ In terms of the melting point, notably, only single sharp endothermic melting peaks were observed for all the conditions, indicating that PLA and PEO were quite miscible for all the given compositions. ${ }^{[17]}$ Moreover, the melting temperature of PLA almost remained unchanged for different compositions of the polymer matrix, suggesting that the addition of PEO had no significant effect on the melting point over the composition range studied. It is because that the existence of PEO can only accelerate the crystal formation by enhancing the mobility of PLA chains, but has limited effect on facilitating the growth of crystallites and thickening of lamellae. ${ }^{[18]}$ Based on all aforementioned morphological, structural, and thermal analyses of the electrospun fibers fabricated from different PLA/PEO weight ratios, those with a weight ratio of 5:5 were chosen for all subsequent experiments, which were expected to afford greater ability in the encapsulation of biomacromolecules.

\subsection{Physical Properties of Composite Fibers with Different CNT Amounts}

Carboxyl-functionalized CNTs with photothermal conversion property was another important element determining the efficiency of biomacromolecule capture. Introduction of carboxyl groups could improve the dispersion stability of CNTs in aqueous media (Figure $\mathrm{S} 1$, Supporting Information). Of note, carboxyl modification was further helpful to make CNTs more biologically compatible with minimum toxicity comparing to unmodified ones. ${ }^{[19]}$ The amount of CNTs should reach a level to induce the pore self-closure upon UV light irradiation. However, with further increase in the CNT concentration exceeding a threshold, the biomacromolecule encapsulation capability of porous electrospun fibers could become negatively influenced by the agglomeration of CNTs. ${ }^{[11]}$ It is worth noting that the photothermal conversion ability of the electrospun fibers could be maximized at the same concentrations of CNTs when CNTs were adsorbed onto the surface of the fibers, compared with those composite films that incorporated CNTs into the polymer matrix by direct mixing. ${ }^{[20]}$ To date, electrospun fibers coated with CNTs have been evaluated for various applications. For example, an approach of immobilizing glucose oxidase onto CNT-coated 
electrospun gold fibers was reported to fabricate a novel biosensor. ${ }^{[21]}$ In this case, $0.25 \mathrm{mg}$ $\mathrm{mL}^{-1}$ of CNTs was chosen to ensure a homogeneous coverage on the fiber surface and to realize a direct electron transfer in a mediator-free state. Additionally, macroporous PLA particles coated with $0.4 \mathrm{mg} \mathrm{mL}^{-1}$ of CNTs were employed for trapping nucleic acids, which exhibited rapid self-closure under NIR light irradiation. ${ }^{[11]}$ Correa-Duarte et al. also reported a convenient method for fabricating nanosensors, where $1.0 \mathrm{mg} \mathrm{mL}^{-1}$ of CNTs were taken into account to improve the electrical conductivity of the composite nanosensors by forming the network between CNTs and the neighboring polymer spheres. ${ }^{[22]}$ Based on these previous studies, $0.2,0.4$, and $0.8 \mathrm{mg} \mathrm{mL}^{-1}$ of CNTs were investigated in the current study to realize a uniform coating while simultaneously achieving a good photothermal effect of CNTs.

Figure 3A shows gross images of the electrospun PLA/CNT composite membranes with different CNT concentrations. The color of the electrospun membranes was observed to become darker with the higher concentrations of CNTs and it was unevenly distributed in the electrospun fibers with $0.8 \mathrm{mg} \mathrm{mL}^{-1}$ of CNTs due to the CNT agglomeration. These results were further supported by the representative SEM images in Figure 3B. When the CNT concentration was as low as $0.2 \mathrm{mg} \mathrm{mL}^{-1}$, only a small amount of CNTs could be seen on the surface of the fibers. As the concentration was increased to $0.4 \mathrm{mg} \mathrm{mL}^{-1}$, much more CNTs were observed, which seemed to disperse homogeneously around the nanopores on the fibers. Nevertheless, with further increase of the CNT concentration to $0.8 \mathrm{mg} \mathrm{mL}^{-1}$, significant agglomeration was observed, and CNTs tended to interact with each other to form the 3D CNT networks rather than distributing on the surface of the fibers. Such a large amount of aggregated CNTs led to a great possibility to block and seal the pores on the surface of the fibers, thus resulting in decreased encapsulation ability of biomacromolecules.

To demonstrate the thermal stability of the electrospun fibers and quantify CNT content in each group, thermogravimetry analysis (TGA) thermograms of the PLA/CNT composite fibers with different CNT concentrations were obtained and are shown in Figure 3C. Due to the random scission of PLA polymer chains, all the curves indicated single weight losses on the decomposition step. ${ }^{[23]}$ Additionally, it should be noted that the temperature at the maximum decomposition rate of the electrospun PLA/CNT fibers was significantly higher than that of the pure PLA samples, suggesting an enhanced thermal stability of the electrospun fibers after incorporation of CNTs. ${ }^{[23]}$ The main reason of this improvement was attributed to the physical barrier effect and the excellent thermal stability of the CNTs, which hindered thermal decomposition of the PLA/CNT composite fibers to a certain degree. ${ }^{[24]}$ TGA was performed to study the quantity of CNTs within the electrospun fibers according to the residual weight at $700{ }^{\circ} \mathrm{C}$. PLA started to degrade at around $300{ }^{\circ} \mathrm{C}$ and completely decomposed at $425^{\circ} \mathrm{C}$, while all of the CNTs were still remained at the temperature of $700{ }^{\circ} \mathrm{C}$ and the residual content of the PLA/CNT fibers increased with the CNT concentration. It is reported that the CNTs are generally stable at $650{ }^{\circ} \mathrm{C}$ and do not decompose until above $750{ }^{\circ} \mathrm{C} .{ }^{[25]}$ Therefore, the residual amounts of the electrospun fibers at $700{ }^{\circ} \mathrm{C}$ should represent the weight percentages of CNTs assembled on the porous electrospun fibers. As shown in the inset in Figure 3C, for the PLA fibers sonicated in 0.2, 0.4 , and $0.8 \mathrm{mg} \mathrm{mL}^{-1}$ of well-dispersed CNT aqueous solutions, the exact amounts of CNTs coated on the fibers were $1.85,3.17$, and $5.86 \mathrm{wt} \%$, respectively. The quantitative analysis of 
CNTs was further performed by measuring the absorbance of electrospun membranes at 650 nm using a microplate reader. ${ }^{[26]}$ As shown in Figure 3D, the electrospun fibers with $0.8 \mathrm{mg}$ $\mathrm{mL}^{-1}$ of CNTs possessed the highest absorbance value of $1.93 \pm 0.22$ a.u., which was $\approx 20 \%$ and $60 \%$ higher than those derived from fibers containing $0.4 \mathrm{mg} \mathrm{mL}^{-1}(1.58 \pm 0.04$ a.u. $)$ and $0.2 \mathrm{mg} \mathrm{mL}^{-1}(1.21 \pm 0.01$ a.u.) CNTs, respectively. In accordance with the microscopic observations and TGA results, the increased absorbance of the composite fibers with increasing CNT concentrations further demonstrated the variation of CNT content within different electrospun fibers. The representative absorbance spectra of electrospun membranes with and without CNTs are presented in Figure S2 (Supporting Information).

The bulk density and porosity of the PLA/CNT membranes with different CNT concentrations were calculated and the results are shown in Figure 4A. As expected, the bulk density of the electrospun membranes increased from 0.17 to $0.32 \mathrm{~g} \mathrm{~cm}^{-3}$ when the CNT concentration was elevated from 0 to $0.8 \mathrm{mg} \mathrm{mL}^{-1}$, since the bulk density of CNTs $(2.1 \mathrm{~g}$ $\left.\mathrm{cm}^{-3}\right)$ is much higher than that of PLA $\left(1.27 \mathrm{~g} \mathrm{~cm}^{-3}\right)$. Noticeably, all the samples showed values of lower than $0.35 \mathrm{~g} \mathrm{~cm}^{-3}$, verifying our porous electrospun membranes had a prominent superiority of being lightweight. ${ }^{[27]}$ Conversely, the porosity exhibited a declining tendency with increasing CNT concentration, which could be ascribed to the presence of extra CNTs scattered among the fibers. In fact, porosity is an important factor that can not only determine the drug encapsulation and release, but also influence the cell proliferation and diffusion of nutrients. ${ }^{[28]}$ The porosities of all our membranes constantly maintained at high levels of above $75 \%$, achieving the requirements for applications in biomacromolecule storage and tissue engineering. ${ }^{[29]}$

The water absorption ability also has a vital importance for porous materials. If the water absorption is overly high, the porous structure of the fibers could be destroyed; on the other hand if it is too low, the diffusion efficiency of the biomacromolecules into the porous structure might be impaired thus affecting the encapsulation ability. ${ }^{[30]}$ As shown in Figure $4 \mathrm{~B}$, the water absorption rate of these fibers decreased significantly from $744.8 \% \pm 55.7 \%$ to $387.2 \% \pm 11.4 \%$ as the fraction of CNTs was elevated from 0 to $0.8 \mathrm{mg} \mathrm{mL}^{-1}$. Consistent with the water uptake results, the contact angles were $123.2^{\circ} \pm 3.5^{\circ}, 128.4^{\circ} \pm 4.1^{\circ}, 132.6^{\circ}$ $\pm 2.7^{\circ}$, and $135.1^{\circ} \pm 5.2^{\circ}$ for fibers with $0,0.2,0.4$, and $0.8 \mathrm{mg} \mathrm{mL}^{-1}$ of CNTs, respectively. Such decreased water absorption rate and increased water contact angle were due to the hydrophobic nature and high interfacial energy of CNTs. ${ }^{[31]}$ Overall, an obvious decrease in the hydrophilicity of the samples was observed by impregnating larger amount of CNTs, which might further exert influence on the degradation behavior, encapsulation of biomacromolecules, as well as cell adhesion on these fibers.

Mechanical properties of the electrospun membranes are one of the crucial parameters for their biomedical applications. Previous studies have demonstrated the improvement of the mechanical performances of electrospun fibers by optimizing the fibrous structures or adding reinforcement elements into the polymer solutions. ${ }^{[32]}$ For the modification of porous fibrous structures, an increased fiber diameter, a reduced porosity, as well as an improved polymer chain orientation are three most effective approaches to enhance the strength of these fibers. ${ }^{[33]}$ In our case, since the fibers acquired in all groups were fabricated using the same polymer composition and under the same processing conditions, the differences shown 
in the mechanical behaviors among the group were primarily caused by CNTs. Figure 4C shows the tensile properties of the PLA/CNT membranes with different CNT concentrations. The results indicated that both the Young's modulus and the tensile strength of the membranes were tremendously improved with the incorporation of CNTs. Particularly, as the CNT amount increased from 0 to $0.4 \mathrm{mg} \mathrm{mL}^{-1}$, the Young's modulus raised from 6.79 \pm 0.68 to $13.47 \pm 3.16 \mathrm{MPa}$, and the corresponding tensile strength improved from 0.69 \pm 0.07 to $1.55 \pm 0.11 \mathrm{MPa}$. It was previously reported that reducing stress concentration and hindering crazing extension were two main methods of CNTs to reinforce the polymer fibers. ${ }^{[34]}$ This significant enhancement in strength was likely related with the efficient load transfer from fibers to the coated CNTs under tensile force, resulting from the interfacial interaction between the polymer fibers and the homogeneously dispersed CNTs. ${ }^{[35]}$ However, as the CNT concentration increased to a level of $0.8 \mathrm{mg} \mathrm{mL}^{-1}$, Young's modulus and tensile strength exhibited small declines to $11.74 \pm 1.27$ and $1.36 \pm 0.06 \mathrm{MPa}$, respectively, compared to those with 0.2 and $0.4 \mathrm{mg} \mathrm{mL}^{-1} \mathrm{CNTs}$, but were still much higher than those of the pure membranes. It is well-known that the dispersion of CNTs in/on polymers can be difficult, since they have a strong tendency to self-agglomerate caused by their large surface-to-volume ratio and the substantial van der Waals interaction. ${ }^{[21]}$ As the composites were subjected to any external force, the large nanoparticle agglomerates may split, leading to a premature failure at the interface of CNTs and polymer fibers. ${ }^{[36]}$ Accordingly, the mechanical properties of the composites tended to fall off slightly with highly concentrated CNTs on the fibers due to poor CNT dispersion and aggregation. Therefore, incorporating CNTs onto the polymer fibers to achieve desired strengthening and stiffening requires meeting two key criteria at the same time, homogeneous dispersion of CNTs on the host fibers and strong interfacial bonding between CNTs and the fibers. ${ }^{[37]}$

Varying the CNT concentrations could also control the degradation rate of the porous composite fibers. As demonstrated in Figure 4D, the in vitro biodegradation studies of the PLA/CNT fibers were conducted during a period of up to 12 weeks. The biodegradation rate presented a decreasing trend with increasing amount of CNTs. For pure PLA samples, the remaining weight of the electrospun fibers was $60.8 \%$ after 12 weeks of incubation. Differently, the PLA/CNT fibers with $0.8 \mathrm{mg} \mathrm{mL}^{-1}$ of CNTs presented the slowest biodegradation kinetics, whose remaining weight was more than $80 \%$ during the same period. It is known that CNTs have been widely used to upregulate the intrinsic surface hydrophobicity by taking advantage of their strong hydrophobic property and the rough nanostructured texture. ${ }^{[38]}$ Herein, the incorporation of CNTs potentially hindered the contact of the fibers with phosphate-buffered saline (PBS) and thus decreased the water molecule diffusion, finally leading to slower hydrolysis of the polyesters. To further investigate the relationship between the in vitro biodegradation rate and the CNT concentration, SEM imaging was also performed. The morphological changes of the PLA/CNT fibers within the biodegradation period are shown in Figure 4E. After 12 weeks of incubation, the fibers without CNTs displayed a more obvious biodegradation, as seen from the appearance of many biodegradation fragments and formation of nanoporous structure on the fiber surface, whereas the composite fibers with CNT incorporation revealed relatively slight surface erosion. These morphological changes of the fibers were in closely 
accordance with the data calculated from weight loss, suggesting that the in vitro biodegradation rate of PLA/CNT fibers could be regulated by different doses of CNTs.

\subsection{Biomacromolecule Trapping and Release Properties}

CNTs have already been demonstrated to convert photoenergy into thermoenergy upon light irradiation due to their wide absorption spectrum, leading to a rapid shape change of the polymer matrix in close proximity. ${ }^{[39]}$ In the current study CNTs were chosen to assemble on the surface of the porous electrospun fibers to realize remote control of the local phase transition of the polymer fibers. Figure 5A shows SEM images of the PLA/CNT fibers with different CNT concentrations after UV light irradiation. Compared with the porous morphology of pure electrospun fibers, most nanopores on the surface of PLA/CNT fibers were closed upon UV light irradiation. In particular, for the fibers with 0.4 and $0.8 \mathrm{mg} \mathrm{mL}^{-1}$ of CNTs, the rapid self-closing capability of the nanopores was more manifested. Basically, self-closure only occurs when the local temperature of the fiber surface is close to the glass transition temperature $\left(T_{\mathrm{g}}\right)$ of the polymer matrix. If the local temperature is much lower than $T_{\mathrm{g}}$, the pore structure will not exhibit a noticeable thermal behavior or an obvious porosity change (as depicted in Figure S3, Supporting Information). ${ }^{[11]}$ Since CNTs were mainly deposited on the surface of the fibers, the $T_{\mathrm{g}}$ of PLA at around $55^{\circ} \mathrm{C}$ should be roughly maintained irrespective of the amount of CNTs. On the other hand, driven by the transfer of potential energy stored in the defects and the minimization of the interfacial energy, the increasing local temperature caused by the photothermal conversion of CNTs allowed the rearrangement and interdiffusion of polymer chains, thereby displaying a selfclosing functionality. ${ }^{[11]}$

To demonstrate the capability of the PLA/CNT fibers to trap biomacromolecules enabled by pore self-closure, FITC-Dex with a molecular weight of $20 \mathrm{kDa}$ was chosen as a model biomacromolecule for encapsulation. The fluorescence images and quantification of fluorescence intensities of the PLA/CNT fibers loaded with FITC-Dex molecules at different CNT concentrations are illustrated in Figure 5B,C, respectively. As expected, few fluorescence signals were detected within the pure electrospun fibers, and only baseline fluorescence intensity was revealed after they were rinsed with water before measurement. In clear contrast, all the PLA/CNT fibers exhibited successful entrapment of FITC-Dex within the porous structures, which could be ascribed to the pore self-closing ability caused by the photothermal conversion of CNTs upon UV light irradiation. The PLA/CNT fibers with $0.4 \mathrm{mg} \mathrm{mL}^{-1}$ of CNTs displayed the highest fluorescence intensity of FITC-Dex (175.0 \pm 4.4 ), almost 2.0 times higher than that of the pure fibers $(57.0 \pm 4.5)$, while those with 0.2 and $0.8 \mathrm{mg} \mathrm{mL}^{-1}$ of CNTs showed intensities of $128.0 \pm 7.0$ and $152.0 \pm 6.8$, respectively. Moreover, the loading efficiencies of FITC-Dex within the pure fibers and the composite fibers with $0.2,0.4$, and $0.8 \mathrm{mg} \mathrm{mL}^{-1}$ of CNTs were calculated to be 4.6, 28.9, 50.7, and $42.1 \mathrm{wt} \%$, respectively. Consistent with the fluorescence intensities, the loading efficiencies also exhibited a first increasing and then decreasing trend with the elevation of the CNT concentration. Such an observation could be due to the fact that, when CNT concentration was $0.2 \mathrm{mg} \mathrm{mL}^{-1}$, the local temperature only increased to $35.4{ }^{\circ} \mathrm{C}$ (Figure S3, Supporting Information) and the corresponding thermal energy was not sufficiently high to realize the self-closure of all the nanopores and thus the encapsulation of FITC-Dex. ${ }^{[4 a]}$ In terms of the 
highest CNT concentration of $0.8 \mathrm{mg} \mathrm{mL}^{-1}$, the nanopores on the fibers were filled with a large amount of aggregated CNTs that might have blocked the entering of biomacromolecules. ${ }^{[11]}$ As a balanced result, $0.4 \mathrm{mg} \mathrm{mL}^{-1}$ of CNTs was determined as the best condition for inducing diffusion of macromolecules and enough local heating to trigger the motion of polymer molecules, leading to effective biomacromolecule encapsulation.

After trapping the biomacromolecules, it is equally important to allow for sustained release of these molecules from the fibers over extended periods of time. The cumulative release profiles of FITC-Dex from the PLA/CNT fibers are plotted in Figure 5D, where an extended release of the molecules for over the period of $15 \mathrm{~d}$ was achieved with relatively low initial burst release within the first $24 \mathrm{~h}$. The PLA/CNT fibers with $0.4 \mathrm{mg} \mathrm{mL}^{-1}$ of CNTs showed the slowest release of FITC-Dex $(52.5 \% \pm 5.2 \%)$ compared with the pure samples $(93.5 \%$ $\pm 4.4 \%$ ) after $15 \mathrm{~d}$. The fast release of FITC-Dex from the pure fibers was because that the biomacromolecules were mainly adsorbed on the fibers and the release was based on a simple desorption mechanism, whereas the fibers with CNTs released FITC-Dex via slowly reopening of the surface nanopores upon degradation of the polymer matrix (Figure 4D,E). Although the fibers with $0.4 \mathrm{mg} \mathrm{mL}^{-1}$ of CNTs degraded faster than that with $0.8 \mathrm{mg} \mathrm{mL}^{-1}$ of CNTs, its higher encapsulation efficiency led to a more sustained release of FITC-Dex. The CNT leaching experiment in PBS was also performed for all the groups, as shown in Figure S4 (Supporting Information). Absorbance values of the CNTs leached out from the electrospun fibers fluctuated from 0.002 to 0.012 a.u. during the $15 \mathrm{~d}$ of storage, indicating that the release behavior of the biomacromolecules was not likely affected by the CNT leaching. In accordance with previous findings, no measureable amount of CNTs was released from the polymer matrix when they were soaked in the neutral solution of PBS. ${ }^{40]}$ Significant leaching of CNTs should only occur under harsh conditions such as in caustic and/or oxidizing solutions (e.g., $\mathrm{NaOH}, \mathrm{NaOCl}$, and $\mathrm{HCl}$ ), which can cause the reordering or breakage of polymer chains and then result in the leaching of CNTs from the electrospun membranes. ${ }^{[40]}$

Electrospun fibers with a core-shell structure is another promising carrier for drug, DNA, and bioactive molecules. ${ }^{[41]}$ Similar to the self-closing electrospun fibers, core-shell fibers can also be conveniently fabricated with electrospinning, using a coaxial dual-capillary spinneret. ${ }^{[42]}$ A series of therapeutic agents spanning from small molecules such as ketoprofen and macromolecules such as growth factors, to mixture of PLGA/BSA can be encapsulated inside the hydrophobic polymer sheath. ${ }^{[42,43]}$ More interestingly, an alleviated initial burst release and a sustained release profile have been realized via the diffusion mechanism, where an impermeable shell provides temporal protection of biomacromolecules in the core until it starts degradation. ${ }^{[44]}$ Despite these similarities, marked differences exist between the two functional electruspun fibers. In some cases, the core aqueous solutions loaded with enzymes or growth factors are not electrospinnable by themselves, because viscosity of the liquid is too low to stretch into the continuous thread within the sheath. In addition, to stabilize the proteins during the coaxial electrospinning, certain water-soluble polymers such as poly(ethylene glycol) (PEG) need to be added as a core component, but the additive PEG in the coaxial structure almost always accelerates the protein release and makes the release kinetics more complex. ${ }^{[43,44]}$ Another disadvantage of core-shell nanofibers is that the long time exposure of bioactive proteins to organic solvent 
at the interface and electrical field during the electrospinning process may potentially impair their biological activities. ${ }^{[43]}$ Most importantly, the remote control of biomacromolecule encapsulation based on the photothermal effect of CNTs cannot be achieved with the coreshell electrospun fibers.

Besides the polysaccharide of FITC-Dex, we also employed TMR-BSA with a molecular weight of $66 \mathrm{kDa}$ as a representative polypeptide to further verify the photothermal encapsulation of the PLA/CNT fibers with $0.4 \mathrm{mg} \mathrm{mL}^{-1}$ of CNTs (Figure 6A). A similar trend was observed with FITC-Dex, where the photothermal encapsulation efficiency of the electrospun fibers was remarkably improved with the addition of CNTs. A rapid self-closure of pores appeared in the PLA/CNT fibers, where $\approx 41.5 \mathrm{wt} \%$ TMR-BSA was successfully loaded and sealed in the porous composite fibers. In comparison, the control sample without CNTs had no response to UV light irradiation and few biomacromolecules was encapsulated inside the porous fibers in an aqueous solution of TMR-BSA. Figure $6 \mathrm{C}$ shows the cumulative release profiles of TMR-BSA from the porous electrospun fibers in PBS, PBS containing 50\% fetal bovine serum (FBS), and FBS. It was interesting to find that the release rate of TMR-BSA was slightly faster in the presence of FBS than that in pure PBS. This phenomenon was possibly related with the existence of albumin in the serum, which was responsible for promoting extensive and rapid hydrolysis of the protein as the major component of serum. Based on the similar compatible principle, a decreased stability of TMR-BSA in FBS resulted in the mildly accelerated release. ${ }^{[45]}$ Additionally, consistent with the extended release of FITC-Dex, TMR-BSA encapsulated within the electrospun PLA/CNT fibers with $0.4 \mathrm{mg} \mathrm{mL}^{-1}$ of CNTs released much more slowly than those directly adsorbed onto the surface of the pure electrospun fibers in all types of release media.

These self-sealing porous polymer materials may have great potential in biomedical applications where entrapment of biomolecules is desired, such as in the case of alleviating inflammation. ${ }^{[1,46]}$ Patients with severe burns or injuries have significantly improved chance of developing uncontrolled inflammation usually caused by the redundant extracellular nucleic acids secreted from dead/dying cells. ${ }^{[43]}$ In this context, these selfsealing porous materials are good candidates for curing inflammatory diseases, since these systems when embedded in the body, could both catch and trap the excessive biomacromolecules such as DNAs and RNAs in a controllable manner. ${ }^{[11]}$ As shown in Figure 6B, the fiber with $0.4 \mathrm{mg} \mathrm{mL}^{-1}$ of CNTs led to successful encapsulation of FLUDNA inside the pores accompanied by a loading efficiency of $42.7 \%$, whereas the pure electrospun fibers were adsorbed by few DNA macromolecules on the fiber surface. Besides trapping undesired biological species, such as bacteria, nucleic acids, and pathological cells, these stimuli-responsive porous structures have also been demonstrated to extend the biomacromolecule release after encapsulation. ${ }^{[11,47]}$ Figure 6D shows the cumulative release profiles of FLU-DNA from the porous electrospun fibers at determined intervals over a period of up to $15 \mathrm{~d}$. Approximately $90 \%$ of FLU-DNA was released from the pure electrospun fibers after immersing the electrospun membranes in PBS for $15 \mathrm{~d}$. In contrast, the release kinetics for the composite PLA/CNT fibers featured a slight burst release within the first $24 \mathrm{~h}(21.3 \% \pm 1.7 \%)$ and a sustained release from day 2 to day $15(49.7 \% \pm 4.2 \%)$, which were primarily dependent on the initial desorption of FLU-DNA from the surface and subsequent reopening of the nanopores, respectively. It is believed that only harsh conditions 
such as low $\mathrm{pH}$ can promote the polymer degradation, and then reopen the closed pores. Therefore, these closed pores are envisioned to sustain for a prolonged period before reopening in a controlled manner in the biological environment, showing a vital importance for the slow release of the encapsulated agents. Overall, these self-closing porous electrospun fibers have demonstrated strong ability in both trapping biomacromolecules and extending their release to potentially relieve the acute negative effects on local microenvironment, and may be extended for trapping nucleic acids for slow release to minimize inflammation.

Carboxyl modification of CNTs can increase the water miscibility by introducing strong hydrophilic groups, so as to further promote the adsorption of various biomacromolecules onto the surface of carboxyl-functionalized CNTs. ${ }^{[48]}$ However, the uptake of biomacromolecules caused by CNTs is highly selective and the loading efficiency depends on several key factors. ${ }^{[49]}$ For example, the hydrogen bonds formed between carboxylfunctionalized CNTs and biomacromolecules can ensure a better adsorption. ${ }^{[50]}$ CNTs with longer lengths and smaller diameters have been shown to enhance the quantity of loaded biomacromolecules. ${ }^{[51]}$ Besides, surface charge of biomacromolecules is crucial in affecting their loading within the PLA/CNT composite fibers due to the electrostatic interactions. ${ }^{[49 a, 51,52]}$ It is reasonable to predict that, the presence of the negatively charged carboxylfunctionalized CNTs would make the electrospun fibers attractive as a porous absorbent for trapping positively charged biomacromolecules. ${ }^{[49 \mathrm{a}]}$ For the biomacromolecules with negative surface charges, they may repel themselves to contact with carboxyl-functionalized CNTs due to the charge-induced steric effects, while some degree of nonspecific adsorption should still occur. ${ }^{[51,52 \mathrm{~b}]}$ In the present study, since FITC-Dex, TMR-BSA, and FLU-DNA bear electrically neutral, negative, and negative charges at physiological $\mathrm{pH}$, respectively, the biomacromolecule loading efficiencies of TMR-BSA and FLU-DNA were $\approx 10 \%$ lower compared to that of FITC-Dex. To further increase the loading efficiency of negatively charged biomacromolecules, some recent studies involved cationic surfactants in the system or applied a direct current to drive the negatively charged biomacromolecules towards the CNT surfaces. ${ }^{[11,49 a]}$

The rapid self-closure of porous materials that is induced by photoirradiation is a minimally invasive and externally controllable way to realize the efficient encapsulation or release of biomacromolecules in biological systems without damaging surrounding healthy tissues. ${ }^{[53]}$ Conventionally, most studies have dealt with UV irradiation to combine with smart photoresponsive polymers, azobenzene derivatives, or polymer/metal nanoparticle composites since UV light apparatus is usually cost-effective, easily set up in laboratory, and has controllable wavelength and intensity. ${ }^{[53,54]}$ Taking advantage of broad wavelength spectrum from 200 to $500 \mathrm{~nm}$ and the effective bactericidal ability of UV light, herein we also employed UV irradiation to regulate the phase transition of polymer substrates based on the photothermal conversion capability of CNTs. ${ }^{[55]}$ An ideal UV power intensity should not damage the living cells nor denature biomacromolecules, but will induce sufficient thermal energy to efficiently trigger the self-closure of surface pores. ${ }^{[4 a]}$ In the current study, the photoinduced encapsulation of biomacromolecules was realized under low-power UV irradiation at $4.07 \mathrm{~W} \mathrm{~cm}^{-2}$ and a wavelength range of $360-480 \mathrm{~nm}$ for $10 \mathrm{~min}$, which has been proven to be a non-toxic intensity level for the cells. ${ }^{[53,56]}$ Additionally, it should be 
noted that the elevated local temperature caused by such low-energy photoirradiation was below $65^{\circ} \mathrm{C}$ (Figure S3, Supporting Information), which should not result in significant degeneration of FITC-Dex, TMR-BSA, or FLU-DNA during the short-term exposure periods. ${ }^{[57]}$ Despite these usefulness, UV irradiation is still mostly suitable for in vitro studies because of its poor penetration in biological tissues. ${ }^{[4 a, 58]}$ Photoirradiation by NIR light is another attractive option to induce phase transition of polymer matrices and significant efforts have been devoted to exploring materials with intense absorption bands in the NIR region (700-1100 nm), including the water-dispersible CNTs functionalized with carboxyl groups. ${ }^{[1,59]}$ It was demonstrated that the absorbed photoenergy could be converted into heat at high efficiency owing to the deep-tissue penetration and low atmosphere absorption of the NIR light. ${ }^{[11,60]}$ We envision the use of NIR light in our future in vivo studies to achieve remote control of biomacromolecule capture.

\subsection{Cytocompatibility of the Electrospun Composite Fibers}

CNTs have shown a great potential in many aspects of biomedical applications due to their remarkable structural, mechanical, and electrical properties. ${ }^{[61]}$ Specifically, for the application of peptide or gene delivery, CNTs covalently conjugated with peptide molecules or DNA at the open ends can serve as a promising carrier system. In addition, the interaction between CNTs and live cells can improve the signal transduction and cell adhesion for tissue engineering applications, such as their use as the coating of orthopedic implants. ${ }^{[62]}$ Some studies have also shown that the increased extracellular $\mathrm{Ca}^{2+}$ level induced by the presence of CNTs can promote the neurite outgrowth and the extension of neurite length by regulating the growth cone motility efficiently. ${ }^{[19 a, 63]}$ However, the use of CNTs in biomedicine is still an area with ongoing debate. Recently, it has been demonstrated that the functionalization of CNTs affects their toxicity. For example, the gold-plated CNTs are more biologically compatible than the unmodified ones so that they can deliver therapeutic agents with minimum toxicity. ${ }^{[39 a]}$ Previous reports have also confirmed the biocompatibility of carboxyl-functionalized CNTs by their promotion of the growth and differentiation of cardiomyocytes and human mesenchymal stem cells, respectively, for a period of $14 \mathrm{~d}$ in vitro. ${ }^{[19 \mathrm{~b}, \mathrm{c}]}$ In the current study, we further examined the biological activity of cells grown on the PLA/CNT fibers to elucidate this concern.

The fluorescence microscopic images of Live/Dead staining on day 7 are shown in Figure 7A. It was proven that the majority of the cells could survive with relatively high viability on these fibers, where a good cytocompatibility of CNTs was exhibited. The cell viability was quantified and plotted in Figure 7C. The cell viability of the fibers with CNTs at $0.4 \mathrm{mg} \mathrm{mL}$ ${ }^{-1}$ was significantly higher than those on the pure fibers. PrestoBlue assay was also conducted to further evaluate the metabolic activity and proliferation of the cells on the fibers (Figure 7D). The PrestoBlue assay indicated that after $24 \mathrm{~h}$ of culture, there was no significant difference in the proliferation of seeded cells among the samples with various CNT concentrations. However, a clear reduction in the cell proliferation was detected on the sample with $0.8 \mathrm{mg} \mathrm{mL}^{-1}$ of CNTs on day 7, compared with samples with 0.2 and $0.4 \mathrm{mg}$ $\mathrm{mL}^{-1}$ of CNTs. According to previous studies, extracellular matrix (ECM) incorporated with CNTs typically shows stronger cell adhesion and a higher cell proliferation rate than pure ECM, which could be ascribed to the strong affinity between CNTs and ECM proteins. ${ }^{[64]}$ 
However, with the gradually increasing amount of CNTs, their agglomeration will affect the biocompatibility and lead to decreased cell proliferation. ${ }^{[65]}$

To examine cell spreading, Alexa Fluor 488-phalloidin and 4',6-diamidino-2-phenylindole (DAPI) staining were further utilized to visualize the F-actin and nuclei of the cells, respectively (Figure 7B). By comparing the samples loaded with various CNT concentrations with non-treated pure samples, it was clear that no obvious difference could be observed for fibers with various CNT concentrations. Combining the results of cell viability, proliferation, and spreading, the PLA/CNT fibers loaded with $0.4 \mathrm{mg} \mathrm{mL}^{-1}$ of CNTs showed slightly better biocompatibility and is promising for future applications in biomacromolecule trapping and release.

\section{Conclusions}

A direct and generally applicable electrospinning/leaching method has been developed to prepare the highly porous PLA/CNT fibers with self-closing functionality. First, samples with different PLA/PEO weight ratios were prepared. The composition of 5:5 led to the formation of the largest pores with an average size of $260 \pm 5 \mathrm{~nm}$, much larger than those of 7:3 $(120 \pm 9 \mathrm{~nm})$ and 3:7 $(90 \pm 11 \mathrm{~nm})$. Considering that the co-continuous porous structure with large pore dimensions could afford great opportunity for the encapsulation of biomacromolecules, fibers fabricated from PLA/PEO weight ratio of 5:5 were chosen for the subsequent experiments. The effects of CNT concentrations at $0,0.2,0.4$, and $0.8 \mathrm{mg} \mathrm{mL}^{-1}$ on fiber morphology, structure, thermal/mechanical, degradation, cell viability, and biomacromolecule encapsulation/release were further investigated. It was found that, the fibers containing $0.4 \mathrm{mg} \mathrm{mL}^{-1}$ of CNTs exhibited a rapid self-closure of the nanopore on the surface of the fibers, the highest encapsulation efficiency, as well as an extended release profile. Meanwhile, the fibers with all CNT concentrations showed similar cell responses indicating their biocompatibility. In summary, the porous electrospun fibers with self-closing capability are not only capable of trapping excess biomacromolecules secreted from injured tissues, but can also extend the release of these encapsulated biomacromolecules to finally eliminate the uncontrolled side effects, such as nucleic acid-sensitive inflammation in the case of wound healing.

Of note, electrospinning is an efficient and versatile process for preparing fibrous materials with micro/nanometer diameters at industrial scales. It has been demonstrated to be a reproducible, stable, portable, and inexpensive method already widely applicable in commercial procedures. In the current study, fabrication of the self-sealing electrospun fibers can be summarized into the following three procedures: electrospinning of the PLA/PEO solution, leaching of PEO dispersed in polymer matrix, and CNT coating on the surface of the fibers. To guarantee the reproducibility and feasibility for large-scale manufacture of such smart photoinduced porous materials, challenges such as the homogeneity of the porous structures and the dispersion ability of CNTs need to be overcome by precisely controlling the electrospinning parameters, stabilizing the critical leaching condition, and modifying CNTs with functional groups. We believe that the present study along with detailed protocols will provide a promising strategy to lead to our ability for large-scale production of these functional materials. In addition, as we realize the poor 
penetration and fast attenuation of UV irradiation in biological tissues, a remote control system based on NIR has been designed for in vivo experiments and will be reported in future publications to provide proof-of-concept data for establishing the potential translation of this smart material into biomedicine.

\section{Experimental Section}

Preparation of Highly Porous Electrospun PLA/CNT Fibers-A convenient, stable, and generally applicable approach was utilized to fabricate the highly porous electrospun fibers with self-closing functionality. PLA (viscosity-average molecular weight $\left(M_{\eta}\right)=79$ $\mathrm{kDa}$ ) and PEO (weight-average molecular weight $\left(M_{\mathrm{w}}\right)=50 \mathrm{kDa}$ ) at various weight ratios of 3:7, 5:5, and 7:3 were dissolved in 7:3 volume ratio of chloroform/dimethylformamide (DMF) with a final polymer concentration of $10 \%(\mathrm{w} / \mathrm{v})$. Then, the polymer solution in a 3.0 $\mathrm{mL}$ plastic syringe with a diameter of $8.66 \mathrm{~mm}$ was injected at a flow rate of $1.0 \mathrm{~mL} \mathrm{~h}^{-1}$ using a syringe pump (Orion M361, Thermo Fisher Scientific, Waltham, MA, USA). The distance between the aluminum foil collector and needle was set as $25 \mathrm{~cm}$ and a $18 \mathrm{kV}$ voltage was generated at room temperature using a direct current power supply (Glassman High Voltage Inc., High Bridge, NJ, USA). The fabricated PLA/PEO fibers were dried in a vacuum oven at $40{ }^{\circ} \mathrm{C}$ for $48 \mathrm{~h}$ to remove residual DMF and chloroform. To obtain the highly porous electrospun fibers, $40.0 \mathrm{mg}$ of PLA/PEO fabrics were immersed into $20.0 \mathrm{~mL}$ of deionized (DI) water at $40{ }^{\circ} \mathrm{C}$ for $7 \mathrm{~d}$. The DI water was replaced 5 times every day to completely remove the PEO component until the weight of fibers remained constant after dried in a vacuum oven. Carboxyl-functionalized CNTs were suspended in DI water and sonicated at $25{ }^{\circ} \mathrm{C}$ for $10 \mathrm{~min}$ using a probe-type ultrasonic homogenizer (Qsonica Sonicator, \#Q500, Newton, CT, USA) (Figure S1, Supporting Information). Subsequently, $40.0 \mathrm{mg}$ of porous PLA fibers were sonicated in a well-dispersed CNT aqueous solution $\left(0.2,0.4\right.$, and $\left.0.8 \mathrm{mg} \mathrm{mL}^{-1}\right)$ for $1 \mathrm{~h}$ using an ultrasonic bath (Health-Sonics, $150 \mathrm{~W}$, \#T1-9C, Pleasanton, CA, USA). Finally, the assembled porous electrospun PLA/CNT fibers were rinsed by DI water and subsequently dried under vacuum at $40{ }^{\circ} \mathrm{C}$ for $48 \mathrm{~h}$.

Physical Characterization of Highly Porous Electrospun PLA/CNT Fibers-The structure and morphology of the electrospun fibers were evaluated by SEM (Model S-570, Hitachi High Technologies Corporation, Tokyo, Japan). The fabricated electrospun fibers were coated with $10 \mathrm{~nm}$ of gold using a sputter coater (Model K550, Emitech, Ashford, Kent, UK) prior to imaging. The images were captured at a $20 \mathrm{kV}$ accelerating voltage. The fiber diameters and pore diameters were measured by Nano Measurer 1.2 software (Informer Technologies Inc., Madrid, MD, Spain) according to the SEM images. The thermal behavior of the electrospun PLA fibers was investigated by differential scanning calorimeter (DSC, TA Q2000 V7.3, TA Instruments, New Castle, DE, USA), where $5.0 \pm 0.2 \mathrm{mg}$ of samples were heated in a nitrogen environment from 40 to $190{ }^{\circ} \mathrm{C}$ at $10{ }^{\circ} \mathrm{C} \mathrm{min}-1$. Melting points were determined from the melting curves as peak temperatures. The percentage of CNTs assembled on the porous electrospun PLA fibers was quantified by TGA (TA Q500, TA Instruments, New Castle, DE, USA). Preweighted fibers at around $10 \pm 0.2 \mathrm{mg}$ were heated from 20 to $700{ }^{\circ} \mathrm{C}$ at a heating rate of $10{ }^{\circ} \mathrm{C} \mathrm{min}-1$ under nitrogen. The density of the porous electrospun PLA/CNT fibers was determined from the ratios of the weights of dried fibers to 
their respective volumes. The porosity of each fibrous membrane was calculated according to Equation (1). The water absorption capacity of the electrospun fibers was determined by incubating preweighted samples in $10.0 \mathrm{~mL}$ of water at $37^{\circ} \mathrm{C}$ for $24 \mathrm{~h}$. A known weight of the sample was placed in DI water. The bulk water was removed by blotting the fiber surface with filter paper and then weighed immediately to obtain wet weight. Then, all samples were completely dried under vacuum at $40{ }^{\circ} \mathrm{C}$ for $24 \mathrm{~h}$ and weighed again. The water absorption rate of the samples was calculated by Equation (2). The contact angle is another quantitative way to evaluate the hydrophilicity of electrospun PLA/CNT fibers, which was measured using a drop shape analyzer (DSA 100, Krüss GmbH, Hamburg, Germany). For each sample, $5.0 \mu \mathrm{L}$ of DI water was dropped carefully onto the electrospun fiber surface, and images of the droplet were automatically recorded to calculate the contact angles. The mechanical properties of electrospun PLA/CNT membranes were determined at $25^{\circ} \mathrm{C}$ and $50 \%$ relative humidity using a uniaxial tensile testing system (Instron, Norwood, MA, USA) at a $5 \mathrm{~mm} \mathrm{~min}^{-1}$ stain rate with a $10 \mathrm{~N}$ load cell. Before testing, the electrospun fibers were cut into rectangular shapes of $0.5 \times 4.0 \mathrm{~cm}^{2}$ in size and $\approx 0.15 \mathrm{~mm}$ in thickness. Young's modulus of the fibers was calculated as the slope of the stress-strain curves within the linear region (strain range, 3-10\%), while the tensile strength was defined as the stress carried at the yield point. For each condition, at least five specimens were tested and the values were averaged. For the in vitro degradation rate, it was determined based on the weight loss of the fibers. The samples $(20.0 \pm 0.2 \mathrm{mg})$ were incubated in $10.0 \mathrm{~mL}$ of PBS $(0.1 \mathrm{M}, \mathrm{pH} 7.4$, Thermo Fisher Scientific, Waltham, MA, USA) at $37{ }^{\circ} \mathrm{C}$ under constant shaking at $75 \mathrm{rpm}$ for up to 12 weeks. PBS was replaced every week. At predetermined time intervals, the samples were carefully removed, rinsed in DI water, lyophilized, and weighed. The degradation percentage of each sample was determined by the ratio of the weight loss and the initial dry weight

$$
\text { Porosity }=\left(1-\frac{\rho}{\rho_{0}}\right) \times 100 \%
$$

where $\rho$ is the density of porous fibers and $\rho_{0}$ is the density of bulk polymer.

$$
\text { Water absorption rate }=\frac{g_{\mathrm{w}}-g_{\mathrm{d}}}{g_{0}} \times 100 \%
$$

where $g_{\mathrm{w}}$ is the wet weight, $g_{\mathrm{d}}$ is the dry weight, and $g_{0}$ is the initial weight of the fibers.

Biomacromolecule Trapping and Release Studies-The electrospun PLA/CNT membranes of $0.15 \mathrm{~mm}$ in thickness were cut into $15 \times 15 \mathrm{~mm}^{2}$ squares and soaked in 5.0 $\mathrm{mL}$ of $0.05 \mathrm{mg} \mathrm{mL}^{-1}$ FITC-Dex, $0.05 \mathrm{mg} \mathrm{mL}^{-1}$ TMR-BSA, and $0.01 \mathrm{mg} \mathrm{mL}^{-1}$ FLU-DNA solutions by stirring at $37^{\circ} \mathrm{C}$ for $24 \mathrm{~h}$. Then each fibrous membrane was subjected to UV light irradiation (Omnicure S2000, EXFO Photonic Solutions Inc., Ontario, Canada) at 4.07 $\mathrm{W} \mathrm{cm}{ }^{-2}$ and a wavelength range of $360-480 \mathrm{~nm}$ for $10 \mathrm{~min}$ to close the surface pores of the electrospun fibers. To remove the residual biomacromolecules physisorbed onto the surface 
of fibers, PBS was subsequently used to rinse the fibers for at least three times. Trapping of FITC-Dex, TMR-BSA, or FLU-DNA within the electrospun PLA/CNT fibers was qualitatively assessed using an inverted fluorescence microscope (Zeiss Axiovert 135, Carl Zeiss, Thornwood, NY, USA). In addition, a microplate reader (BioTek Instruments, Winooski, VT, USA) was employed for quantitative analysis of biomacromolecule loading efficiency. The leftover solution and all PBS washes were collected to measure the amount of desorbed biomacromolecules, and the loading content was calculated as the difference between the amounts of total and desorbed biomacromolecules. The loading efficiency of the electrospun membrane was determined as the weight ratio of loading content to total amount of biomacromolecules added.

After trapping the FITC-Dex, TMR-BSA, and FLU-DNA inside the electrospun fibers by UV light irradiation for $10 \mathrm{~min}$, the in vitro release studies of FITC-Dex and FLU-DNA from the electrospun PLA/CNT fibers were carried out in PBS at $37{ }^{\circ} \mathrm{C}$ under the constant agitation for up to $15 \mathrm{~d}$. Additionally, to mimic the protein contents and properties of a real physiological condition, the release assays of TMR-BSA were conducted in different release media of PBS, PBS containing 50\% FBS, and FBS. At predetermined time intervals, 100.0 $\mu \mathrm{L}$ of the release medium was withdrawn to determine the amount of released biomacromolecules and replaced with fresh buffer to maintain the sink condition. The concentrations of FITC-Dex, TMR-BSA, and FLU-DNA were determined by measuring the fluorescence intensity with excitation/emission wavelength at 495/520,541/572, and $495 / 520 \mathrm{~nm}$, respectively, using a microplate reader. The standard curves for the FITC-Dex, TMR-BSA, and FLU-DNA quantification are presented in Figure S5 (Supporting Information).

\section{Adhesion, Proliferation, and Spreading of Cells on the Electrospun Fibers-} The electrospun PLA/CNT fibers were seeded with C2C12 mouse myoblasts (American Type Culture Collection, ATCC, Manassas, VA, USA) and cultured using standard sterile techniques. Before cell seeding, PLA/CNT samples were placed in the wells of standard 24 well plates, washed with 70\% ethanol, rinsed twice with PBS, air-dried under sterile conditions, and UV-irradiated for overnight. The cells were seeded directly on top of the fibers and the media were added, after which the samples were kept at $37{ }^{\circ} \mathrm{C}$ and $5 \% \mathrm{CO}_{2}$ in a humidified incubator. Cell viability was determined using the Live/Dead assay kit (Thermo Fisher Scientific, Waltham, MA, USA) according to the manufacturer's instructions. Briefly, the cells were stained with calcein AM $\left(0.5 \mu \mathrm{L} \mathrm{mL}^{-1}\right)$ for live cells and ethidium homodimer-1 (EthD-1, $2 \mu \mathrm{L} \mathrm{mL}^{-1}$ ) for dead cells in PBS. The cells were incubated at $37{ }^{\circ} \mathrm{C}$ for $20 \mathrm{~min}$, and rinsed with PBS thrice to finish the staining. The stained cells were observed using an inverted fluorescence microscope. For each experimental condition, images from at least 4 different areas of 3 samples were employed for counting the numbers of live and dead cells by the ImageJ software (National Institutes of Health, Bethesda, MD, USA). Cell viability was calculated as the number of live cells divided by the total cell number. For the metabolic PrestoBlue assay, cell viability was measured on days 1,3, and 7 of culture per manufacturer's instructions. Briefly, a total of $50.0 \mu \mathrm{L}$ of working reagent was added to each well and incubated for $3 \mathrm{~h}$ at $37^{\circ} \mathrm{C}$. The absorbance of incubated sample was read at $570 \mathrm{~nm}$ for excitation and $600 \mathrm{~nm}$ for emission on a spectrophotometer (BioTek Instruments, 
Winooski, VT, USA). Alexa Fluor 488-phalloidin and DAPI (Thermo Fisher Scientific, Waltham, MA, USA) were used to stain the cells for F-actin and nuclei, respectively, for investigating cell adhesion on the surfaces of the electrospun PLA/CNT fibers. Cells seeded on different substrates were fixed in 4 vol.\% paraformaldehyde for $30 \mathrm{~min}$, followed by treatment with a $0.1 \%(\mathrm{w} / \mathrm{v})$ Triton X-100 solution in PBS for $20 \mathrm{~min}$ to increase the permeability, and with a $1 \%(w / v)$ BSA (Sigma-Aldrich, St. Louis, MO, USA) solution in PBS for $1 \mathrm{~h}$ to block non-specific binding sites. The cells were incubated at room temperature in a 1:40 dilution of Alexa Fluor 488-phalloidin in $0.1 \%$ (w/v) BSA for 45 min to stain the F-actin, and then incubated at $37{ }^{\circ} \mathrm{C}$ in a $0.1 \%$ (w/v) DAPI solution in PBS for 10 min to stain the cell nuclei. After each staining step, the samples were thoroughly washed with PBS thrice before visualizing with the fluorescence microscope.

Statistical Analyses-To ensure reproducibility, all tests were repeated at least thrice and the average values and standard deviations were obtained. All data were represented as the mean \pm standard deviation $(n=3)$. The one-way analysis of variance (ANOVA) was employed to analyze the data by the statistical software SPSS 13.0 (SPSS Inc., Chicago, IL, USA). A probability value of less than 0.05 was considered significantly different and those below 0.01 and 0.001 were considered highly significantly different.

\section{Supplementary Material}

Refer to Web version on PubMed Central for supplementary material.

\section{Acknowledgments}

J.Z. and T.Z. contributed equally to this work. The authors gratefully acknowledge the financial support from the Program of National Natural Science Foundation of China (Grant Nos. 51120135002, 51421061, 51673190, 51673187, and 51520105004). Y.S.Z. acknowledges the National Cancer Institute of the National Institutes of Health Pathway to Independence Award (K99CA201603). The authors also acknowledge the support provided by the China Scholarship Council during a visit of J.Z. to Harvard Medical School (No. 201506240072) and a postdoc research grant from the Scientific and Technological Research Council of Turkey to E.A. (1059B191500017).

\section{References}

1. a) Yang XY, Chen LH, Li Y, Rooke JC, Sanchez C, Su BL. Chem Soc Rev. 2017; 46:481. [PubMed: 27906387] b) Gao L, Li CYV, Chan KY, Chen ZN. J Am Chem Soc. 2014; 136:7209. [PubMed: 24802277]

2. Fasano V, Baroncini M, Moffa M, Iandolo D, Camposeo A, Credi A, Pisignano D. J Am Chem Soc. 2014; 136:14245. [PubMed: 25264943]

3. Baroncini M, d'Agostino S, Bergamini G, Ceroni P, Comotti A, Sozzani P, Bassanetti I, Grepioni F, Hernandez TM, Silvi S, Venturi M, Credi A. Nat Chem. 2015; 7:634. [PubMed: 26201739]

4. a) Yang X, Liu X, Liu Z, Pu F, Ren J, Qu X. Adv Mater. 2012; 24:2890. [PubMed: 22539076] b) Stuart MAC, Huck WTS, Genzer J, Müller M, Ober C, Stamm M, Sukhorukov GB, Szleifer I, Tsukruk VV, Urban M. Nat Mater. 2010; 9:101. [PubMed: 20094081]

5. Vasani RB, McInnes SJP, Cole MA, Jani AMM, Ellis AV, Voelcker NH. Langmuir. 2011; $27: 7843$. [PubMed: 21604788]

6. a) Lee Y, Sah H. J Mater Sci. 2016; 51:6257.b) Fan D, De Rosa E, Murphy MB, Peng Y, Smid CA, Chiappini C, Liu X, Simmons P, Weiner BK, Ferrari M. Adv Funct Mater. 2012; 22:282.

7. Lee JH, Kim H, Kim JH, Lee SH. Lab Chip. 2016; 16:959. [PubMed: 26891410] 
8. a) Kim J, Joo SS, Lee KW, Kim JH, Shin DH, Kim S, Choi SH. ACS Appl Mater Interfaces. 2014; 6:20880. [PubMed: 25384018] b) Yavuz MS, Cheng Y, Chen J, Cobley CM, Zhang Q, Rycenga M, Xie J, Kim C, Song KH, Schwartz AG. Nat Mater. 2009; 8:935. [PubMed: 19881498]

9. Hu L, Gao S, Ding X, Wang D, Jiang J, Jin J, Jiang L. ACS Nano. 2015; 9:4835. [PubMed: 25905455]

10. Miyako E, Nagata H, Hirano K, Hirotsu T. Small. 2008; 4:1711. [PubMed: 18770507]

11. Qian Q, Huang X, Zhang X, Xie Z, Wang Y. Angew Chem, Int Ed. 2013; 52:10625.

12. Kim A, Ou FS, Ohlberg DAA, Hu M, Williams RS, Li Z. J Am Chem Soc. 2011; 133:8234. [PubMed: 21520938]

13. Lins LC, Wianny F, Livi S, Hidalgo IA, Dehay C, Duchet-Rumeau J, Gerard J-F. Biomacromolecules. 2016; 17:3172. [PubMed: 27629596]

14. Sarazin P, Roy X, Favis BD. Biomaterials. 2004; 25:5965. [PubMed: 15183611]

15. Bai Y, Huang ZH, Kang F. Carbon. 2014; 66:705.

16. Adjei IM, Sharma B, Peetla C, Labhasetwar V. J Controlled Release. 2016; 232:83.

17. Zolali AM, Heshmati V, Favis BD. Macromolecules. 2017; 50:264.

18. Xu J, Heck B, Ye HM, Jiang J, Tang YR, Liu J, Guo BH, Reiter R, Zhou DS, Reiter Gn. Macromolecules. 2016; 49:2206.

19. a) Monteiro Riviere NA, Inman AO. Carbon. 2006; 44:1070.b) Shin SR, Jung SM, Zalabany M, Kim K, Zorlutuna P, Kim SB, Nikkhah M, Khabiry M, Azize M, Kong J, Wan KT, Palacios T, Dokmeci MR, Bae H, Tang X, Khademhosseini A. ACS Nano. 2013; 7:2369. [PubMed: 23363247] c) Kharaziha M, Shin SR, Nikkhah M, Topkaya SN, Masoumi N, Annabi N, Dokmeci MR, Khademhosseini A. Biomaterials. 2014; 35:7346. [PubMed: 24927679]

20. Kim HS, Jin HJ, Myung SJ, Kang M, Chin IJ. Macromol Rapid Commun. 2006; 27:146.

21. Jose MV, Marx S, Murata H, Koepsel RR, Russell AJ. Carbon. 2012; 50:4010.

22. Correa-Duarte MA, Kosiorek A, Kandulski W, Giersig M, Salgueirño-Maceira V. Small. 2006; 2:220. [PubMed: 17193024]

23. Armentano I, Bitinis N, Fortunati E, Mattioli S, Rescignano N, Verdejo R, Lopez-Manchado MA, Kenny JM. Prog Polym Sci. 2013; 38:1720.

24. Habisreutinger SN, Leijtens T, Eperon GE, Stranks SD, Nicholas RJ, Snaith HJ. Nano Lett. 2014; 14:5561. [PubMed: 25226226]

25. Sainz R, Benito AM, Martínez MT, Galindo JF, Sotres J, Baró AM, Corraze B, Maser WK. Adv Mater. 2005; 17:278.

26. a) Tanaka T, Jin H, Miyata Y, Fujii S, Suga H, Naitoh Y, Minari T, Miyadera T, Tsukagoshi K, Kataura H. Nano Lett. 2009; 9:1497. [PubMed: 19243112] b) Zheng M, Diner BA. J Am Chem Soc. 2004; 126:15490. [PubMed: 15563177]

27. Ling J, Zhai W, Feng W, Shen B, Zhang J, Zheng Wg. ACS Appl Mater Interfaces. 2013; 5:2677. [PubMed: 23465462]

28. Horcajada P, Chalati T, Serre C, Gillet B, Sebrie C, Baati T, Eubank JF, Heurtaux D, Clayette P, Kreuz C. Nat Mater. 2010; 9:172. [PubMed: 20010827]

29. Thavornyutikarn B, Chantarapanich N, Sitthiseripratip K, Thouas GA, Chen Q. Prog Biomater. 2014; 3:61. [PubMed: 26798575]

30. Feng X, Liu L, Wang S, Zhu D. Chem Soc Rev. 2010; 39:2411. [PubMed: 20571669]

31. Walther JH, Ritos K, Cruz-Chu ER, Megaridis CM, Koumoutsakos P. Nano Lett. 2013; 13:1910. [PubMed: 23521014]

32. a) Sen R, Zhao B, Perea D, Itkis ME, Hu H, Love J, Bekyarova E, Haddon RC. Nano Lett. 2004; 4:459.b) Papkov D, Zou Y, Andalib MN, Goponenko A, Cheng SZD, Dzenis YA. ACS Nano. 2013; 7:3324. [PubMed: 23464637]

33. Huang L, Arena JT, Manickam SS, Jiang X, Willis BG, McCutcheon JR. J Membrane Sci. 2014; 460:241.

34. Ko F, Gogotsi Y, Ali A, Naguib N, Ye H, Yang GL, Li C, Willis P. Adv Mater. 2003; 15:1161.

35. Lu P, Hsieh YL. ACS Appl Mater Interfaces. 2010; 2:2413. [PubMed: 20669908]

36. Chen Y, Zhang HB, Yang Y, Wang M, Cao A, Yu ZZ. Adv Funct Mater. 2016; 26:447. 
37. Sen R, Zhao B, Perea D, Itkis ME, Hu H, Love J, Bekyarova E, Haddon RC. Nano Lett. 2004; $4: 459$.

38. Moura FCC, Lago RM. Appl Catal, B. 2009; 90:436.

39. a) Kim JW, Galanzha EI, Shashkov EV, Moon HM, Zharov VP. Nat Nanotechnol. 2009; 4:688. [PubMed: 19809462] b) Arnold MS, Zimmerman JD, Renshaw CK, Xu X, Lunt RR, Austin CM, Forrest SR. Nano Lett. 2009; 9:3354. [PubMed: 19637853]

40. a) de Lannoy CF, Soyer E, Wiesner MR. J Membr Sci. 2013; 447:395.b) Kim ES, Hwang G, ElDin GMG, Liu Y. J Membr Sci. 2012; 394:37.c) Khalid A, Al-Juhani AA, Al-Hamouz OC, Laoui T, Khan Z, Atieh MA. Desalination. 2015; 367:134.

41. Jiang H, Wang L, Zhu K. J Controlled Release. 2014; 193:296.

42. Zhang H, Zhao Y, Han F, Wang M, Yuan X. J Controlled Release. 2011; 152:181.

43. Ji W, Yang F, van den Beucken JJJP, Bian Z, Fan M, Chen Z, Jansen JA. Acta Biomater. 2010; 6:4199. [PubMed: 20594971]

44. a) Jiang H, Hu Y, Li Y, Zhao P, Zhu K, Chen W. J Controlled Release. 2005; 108:237.b) Zhang YZ, Wang X, Feng Y, Li J, Lim CT, Ramakrishna S. Biomacromolecules. 2006; 7:1049. [PubMed: 16602720]

45. a) Arora S, Swaminathan SK, Kirtane A, Srivastava SK, Bhardwaj A, Singh S, Panyam J, Singh AP. Int J Nanomed. 2014; 9:2933.b) Shahbazi MA, Shrestha N, Mäkilä E, Araújo F, Correia A, Ramos T, Sarmento B, Salonen J, Hirvonen J, Santos HA. Nano Res. 2015; 8:1505.c) Opanasopit P, Yokoyama M, Watanabe M, Kawano K, Maitani Y, Okano T. J Controlled Release. 2005; 104:313.

46. Holl EK, Shumansky KL, Borst LB, Burnette AD, Sample CJ, Ramsburg EA, Sullenger BA. Proc Natl Acad Sci USA. 2016; 113:9728. [PubMed: 27528673]

47. Fernandes R, Gracias DH. Adv Drug Delivery Rev. 2012; 64:1579.

48. Zhang Y, Bai Y, Yan B. Drug Discovery Today. 2010; 15:428. [PubMed: 20451656]

49. a) Foldvari M, Bagonluri M. Nanomed Nanotechnol. 2008; 4:183.b) Burch HJ, Contera SA, de Planque MRR, Grobert N, Ryan JF. Nanotechnology. 2008; 19:384001. [PubMed: 21832561]

50. Feng W, Ji P. Biotechnol Adv. 2011; 29:889. [PubMed: 21820044]

51. Kulkarni M, Mazare A, Park J, Gongadze E, Killian MS, Kralj S, von der Mark K, Igli_a A, Schmuki P. Acta Biomater. 2016; 45:357. [PubMed: 27581395]

52. a) Kotchey GP, Zhao Y, Kagan VE, Star A. Adv Drug Delivery Rev. 2013; 65:1921.b) Hebbar RS, Isloor AM, Ananda K, Ismail AF. J Mater Chem A. 2016; 4:764.

53. Vivero-Escoto JL, Slowing II, Wu CW, Lin VS-Y. J Am Chem Soc. 2009; 131:3462. [PubMed: 19275256]

54. a) Tomatsu I, Hashidzume A, Harada A. Macromolecules. 2005; 38:5223.b) Wang C, Flynn NT, Langer R. Adv Mater. 2004; 16:1074.c) Liu G, Liu W, Dong CM. Polym Chem. 2013; 4:3431.d) Yan X, Wang F, Zheng B, Huang F. Chem Soc Rev. 2012; 41:6042. [PubMed: 22618080]

55. Buonanno M, Randers-Pehrson G, Bigelow AW, Trivedi S, Lowy FD, Spotnitz HM, Hammer SM, Brenner DJ. PloS One. 2013; 8:e76968. [PubMed: 24146947]

56. a) Yan H, Teh C, Sreejith S, Zhu L, Kwok A, Fang W, Ma X, Nguyen KT, Korzh V, Zhao Y. Angew Chem, Int Ed. 2012; 124:8498.b) Mironi-Harpaz I, Wang DY, Venkatraman S, Seliktar D. Acta Biomater. 2012; 8:1838. [PubMed: 22285429]

57. a) Militello V, Casarino C, Emanuele A, Giostra A, Pullara F, Leone M. Biophys Chem. 2004; 107:175. [PubMed: 14962598] b) Cassano R, Trombino S, Muzzalupo R, Tavano L, Picci N. Eur J Pharm Biopharm. 2009; 72:232. [PubMed: 18976708]

58. You J, Shao R, Wei X, Gupta S, Li C. Small. 2010; 6:1022. [PubMed: 20394071]

59. Wu L, Wu M, Zeng Y, Zhang D, Zheng A, Liu X, Liu J. Nanotechnology. 2014; 26:025102. [PubMed: 25517859]

60. Wang J, Zhao J, Li Y, Yang M, Chang Y-Q, Zhang J-P, Sun Z, Wang Y. ACS Macro Lett. 2015; 4:392.

61. Keefer EW, Botterman BR, Romero MI, Rossi AF, Gross GW. Nat Nanotechnol. 2008; 3:434. [PubMed: 18654569]

62. Jan E, Kotov NA. Nano Lett. 2007; 7:1123. [PubMed: 17451277] 
63. Jin GZ, Kim M, Shin US, Kim HW. Cell Biol Int. 2011; 35:741. [PubMed: 21332449]

64. a) Namgung S, Kim T, Baik KY, Lee M, Nam JM, Hong S. Small. 2011; 7:56. [PubMed: 21061404] b) Shin SR, Bae H, Cha JM, Mun JY, Chen YC, Tekin H, Shin H, Farshchi S, Dokmeci MR, Tang S. ACS Nano. 2011; 6:362. [PubMed: 22117858]

65. Mooney E, Dockery P, Greiser U, Murphy M, Barron V. Nano Lett. 2008; 8:2137. [PubMed: 18624387] 

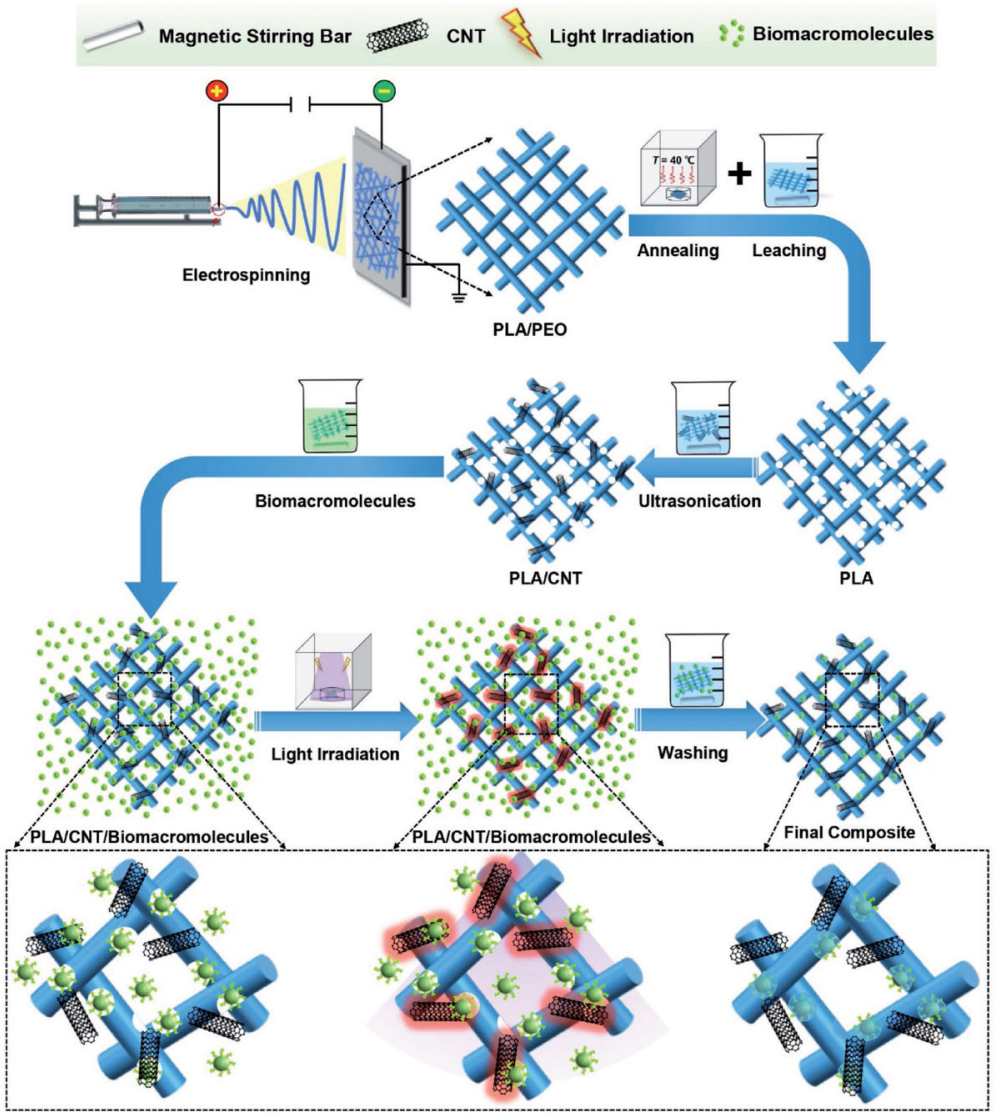

Figure 1.

Schematic showing fabrication procedures of porous electrospun PLA/CNT fibers with selfsealing pores for controlled trapping of biomacromolecules. 


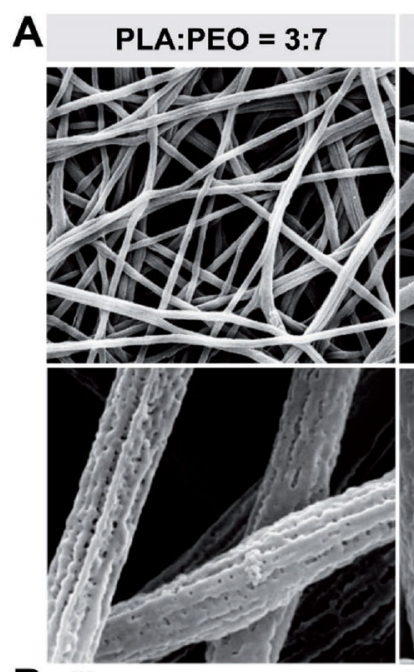

PLA:PEO $=5: 5$
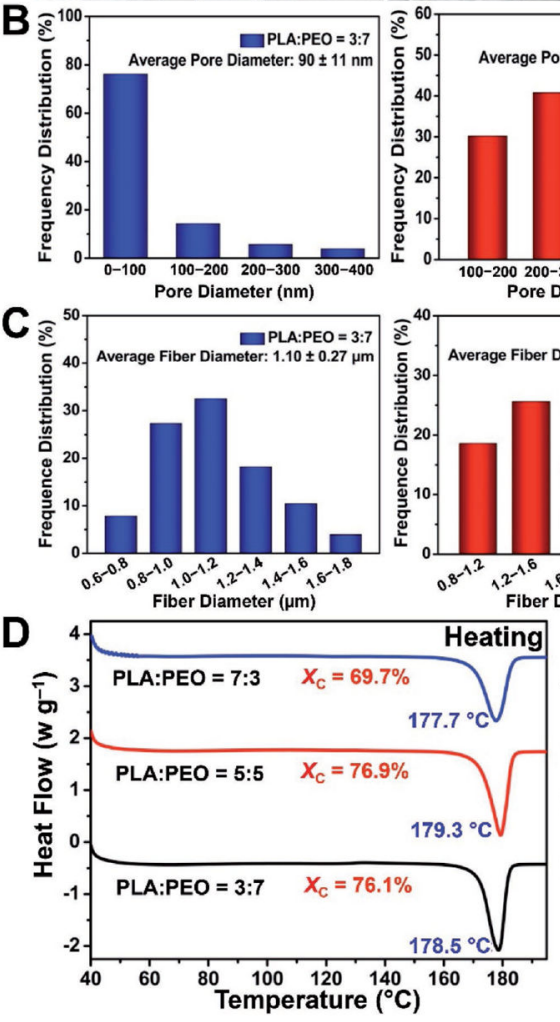
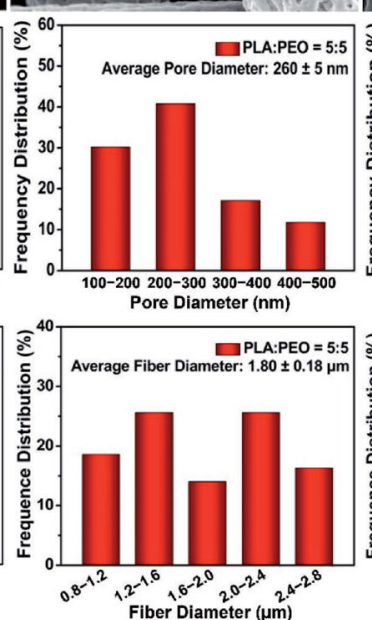

PLA:PEO $=7: 3$
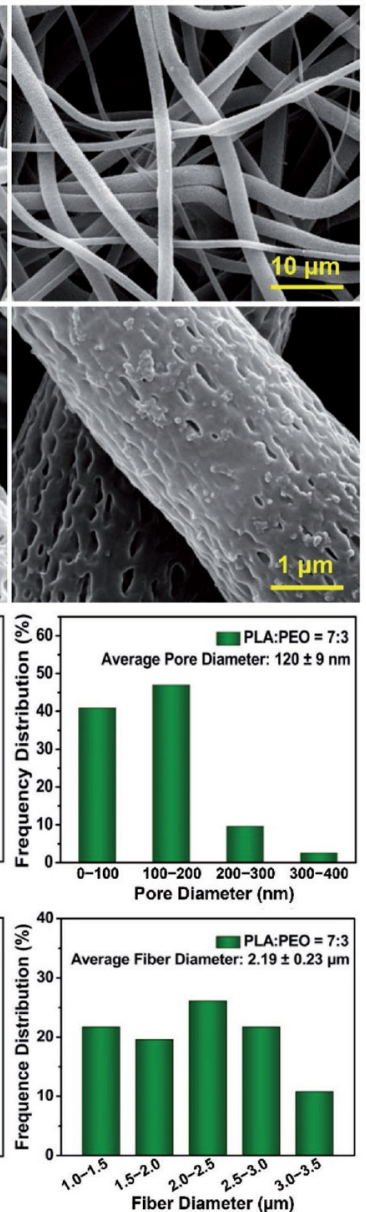

Figure 2.

Characterizations of electrospun fibers with different PEO contents. A) Representative SEM

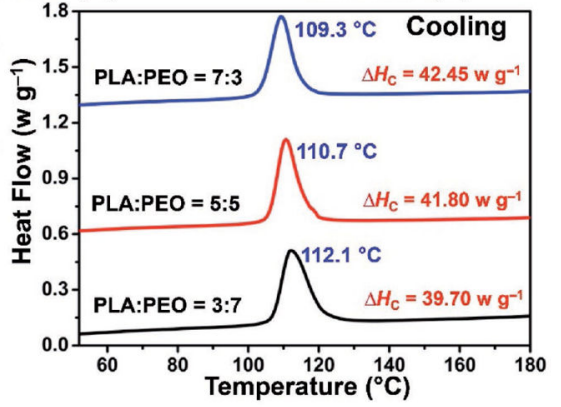
micrographs. B) Average pore sizes and frequency distributions. C) Average fiber diameters and frequency distributions. D) DSC heating and cooling curves of electrospun fibers fabricated with different PLA/PEO weight ratios. 


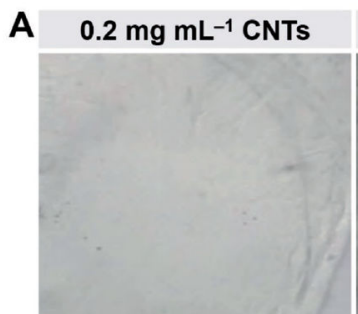

$0.4 \mathrm{mg} \mathrm{mL}^{-1} \mathrm{CNTs}$

$0.8 \mathrm{mg} \mathrm{mL}^{-1} \mathrm{CNTs}$

B $\quad 0.2 \mathrm{mg} \mathrm{mL}^{-1} \mathrm{CNTs}$
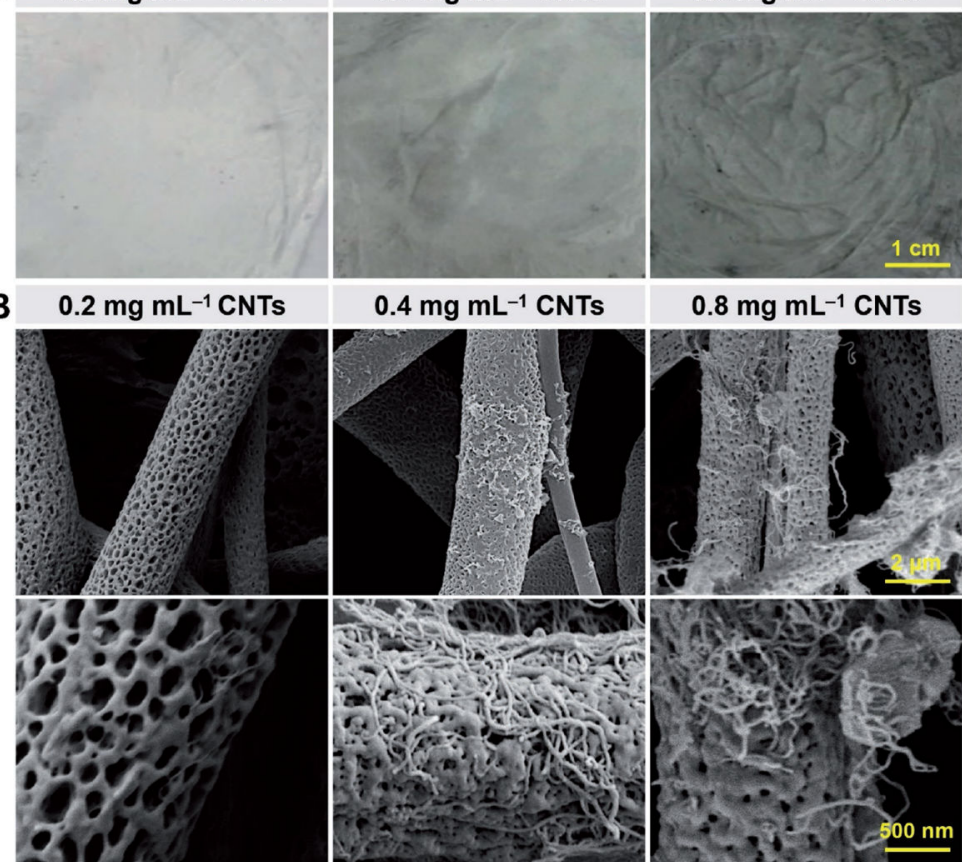

$0.4 \mathrm{mg} \mathrm{mL}^{-1}$ CNTs

$0.8 \mathrm{mg} \mathrm{mL}^{-1} \mathrm{CNTs}$
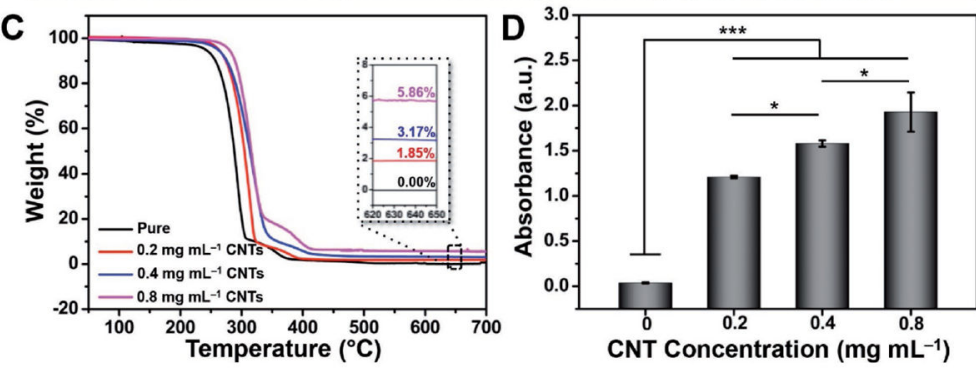

Figure 3.

Characterizations of electrospun fibers with different CNT amounts. A) Gross images and B) representative SEM micrographs of PLA/CNT composite fibers. C) TGA thermograms under a nitrogen atmosphere and D) absorbance at $650 \mathrm{~nm}$ measured by microplate reader of electrospun PLA/CNT fibers with different CNT concentrations. Results are presented as means \pm standard deviations $(n=3 ; * p<0.05, * * p<0.01$, and $* * * p<0.001)$. 

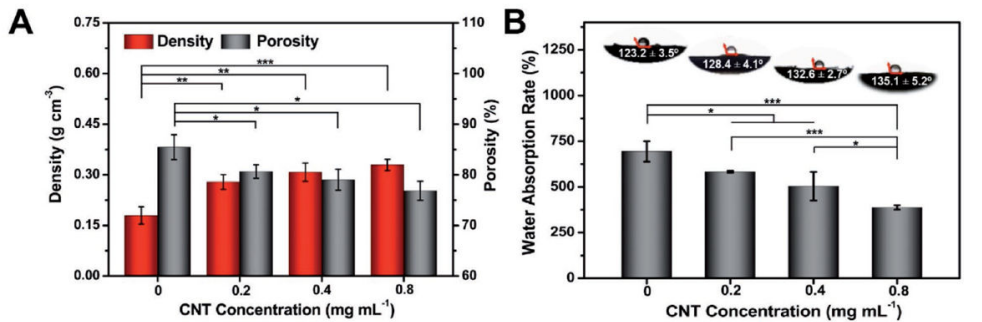

C
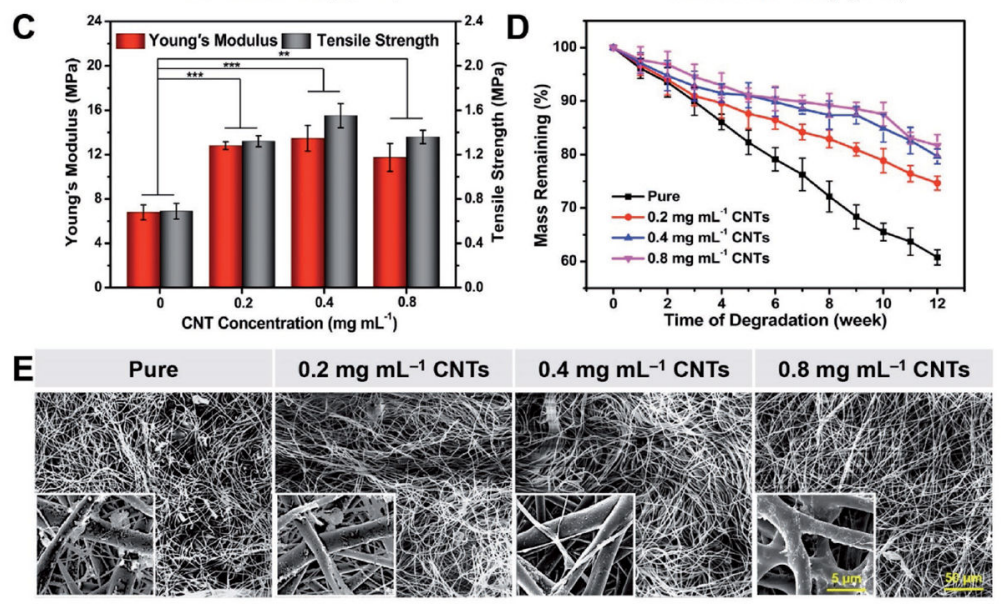

Figure 4.

Characterizations of density, porosity, hydrophilicity, tensile, and degradation properties of PLA/CNT fibers. A) Density and porosity of PLA/CNT fibers. B) Water absorption rates and contact angle images of fibers with different CNT concentrations. C) Tensile properties of PLA/CNT fibers with different CNT concentrations. D) Degradation behavior of fibers. E) SEM images showing morphological changes of PLA/CNT fibers with 0, 0.2, 0.4, and $0.8 \mathrm{mg} \mathrm{mL}^{-1} \mathrm{CNT}$ concentrations for up to 12 weeks. Insets depict the high-resolution micrograph of the electrospun fibers. Results are presented as means \pm standard deviations $(n=3 ; * p<0.05, * * p<0.01$, and $* * * p<0.001)$. 

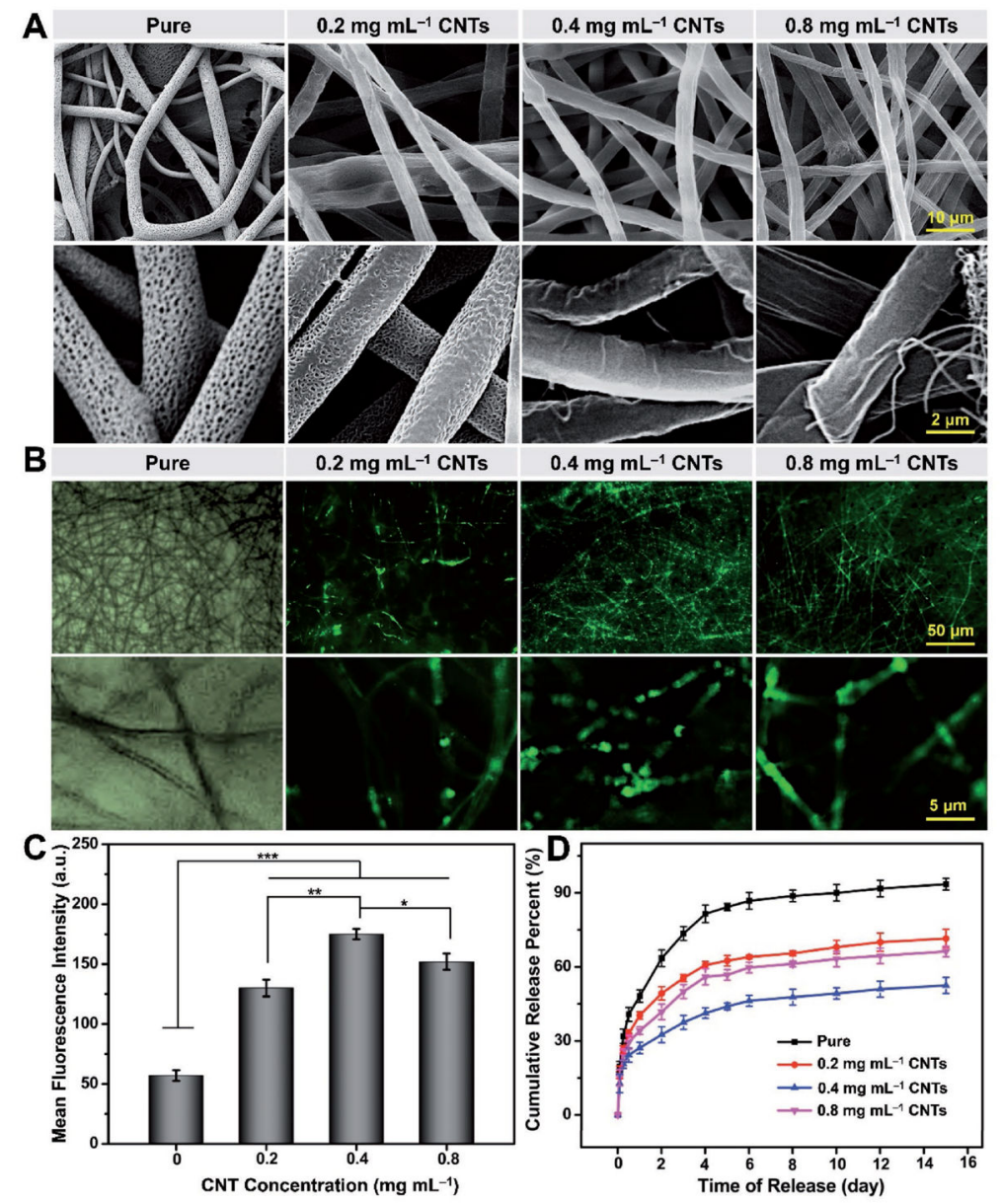

Figure 5.

FITC-Dex encapsulation and sustained release properties. A) SEM and B) fluorescence images of PLA/CNT fibers with different CNT concentrations after UV light irradiation. C) Mean fluorescence intensities of PLA/CNT fibers loaded with FITC-Dex molecules at different CNT concentrations. D) FITC-Dex release curves of PLA/CNT fibers with different CNT concentrations after incubation in PBS at $37{ }^{\circ} \mathrm{C}$. Results are presented as means \pm standard deviations $(n=3 ; * p<0.05, * * p<0.01$, and $* * * p<0.001)$. 


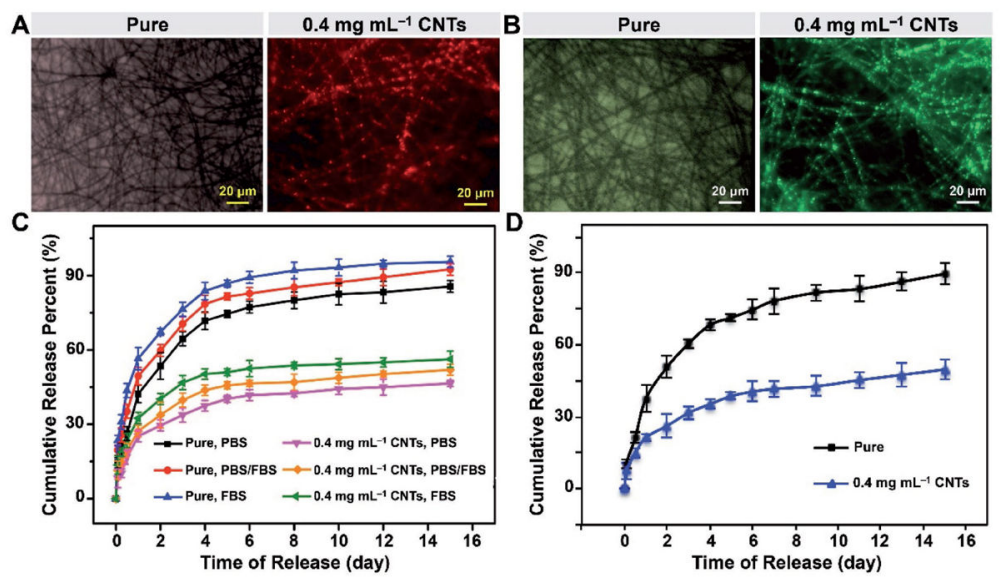

Figure 6.

TMR-BSA and FLU-DNA encapsulation and release properties. A) TMR-BSA and B) FLUDNA fluorescence images of pure electrospun fibers and electrospun PLA/CNT fibers with $0.4 \mathrm{mg} \mathrm{mL}^{-1}$ of CNTs after UV light irradiation. C) TMR-BSA and D) FLU-DNA release profiles from pure electro-spun fibers and electrospun PLA/CNT fibers with $0.4 \mathrm{mg} \mathrm{mL}^{-1}$ of CNTs after incubation in the release media at $37{ }^{\circ} \mathrm{C}$ for $15 \mathrm{~d}$. Results are presented as means \pm standard deviations $(n=3 ; * p<0.05, * * p<0.01$, and $* * * p<0.001)$. 


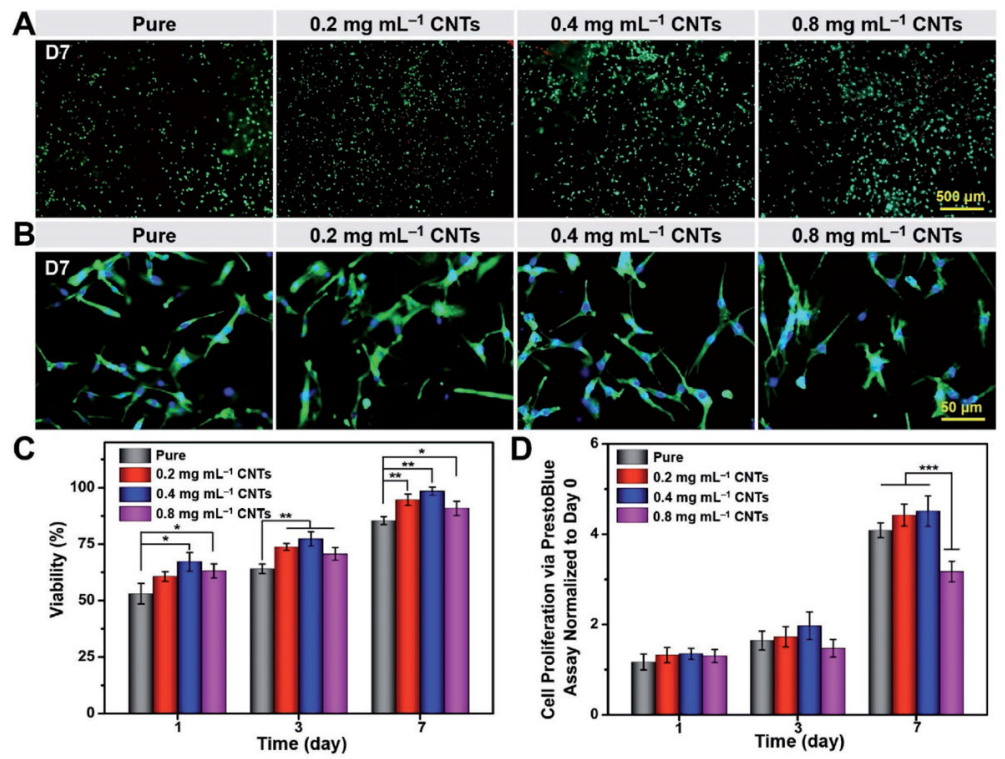

Figure 7.

Viability, proliferation, and spreading behavior of myoblasts. A) Representative fluorescence images of Live/Dead staining for cell viability. B) F-actin/nuclei staining for cell spreading on fibers on day 7 postculture. C) Viability of myoblasts seeded on fibers on days 1, 3, and 7. D) Cell proliferation on fibers on days 1, 3, and 7 determined by PrestoBlue assay. Results are presented as means \pm standard deviations $(n=3 ; * p<0.05, * * p<0.01$, and $* * * p<$ $0.001)$. 